\title{
Hydrogen Generation from Alcohols Catalyzed by Ruthenium-Triphenylphosphine Complexes: Multiple Reaction Pathways
}

\begin{tabular}{|r|l|}
\hline Journal: & Journal of the American Chemical Society \\
\hline Manuscript ID: & ja-2010-01044c.R1 \\
\hline Manuscript Type: & Article \\
\hline Aute Submitted by the & \\
\hline Complete List of Authors: & $\begin{array}{l}\text { Sieffert, Nicolas; University of St. Andrews } \\
\text { Buehl, Michael; University of St. Andrews }\end{array}$ \\
\hline
\end{tabular}

\section{scholarONE" \\ Manuscript Central}


Version 1.4.2010

\title{
Hydrogen Generation from Alcohols Catalyzed by Ruthenium-Triphenylphosphine Complexes: Multiple Reaction Pathways.
}

\author{
Nicolas Sieffert and Michael Bühl* \\ University of St. Andrews. School of Chemistry. North Haugh. \\ St. Andrews. Fife. KY16 9ST. Scotland. United Kingdom. \\ E-mail: buehl@st-andrews.ac.uk.
}

\begin{abstract}
We report a comprehensive density functional theory (DFT) study of the mechanism of the methanol dehydrogenation reaction catalyzed by $\left[\mathrm{RuH}_{2}\left(\mathrm{H}_{2}\right)\left(\mathrm{PPh}_{3}\right)_{3}\right]$. Using the B97-D dispersion-corrected functional, four pathways have been fully characterized, which differ in the way the critical $\beta$-hydrogen transfer step is brought about (e.g. by prior dissociation of one $\mathrm{PPh}_{3}$ ligand). All these pathways are found to be competitive $\left(\Delta \mathrm{G}^{\ddagger}=27.0\right.$ to $32.1 \mathrm{kcal} / \mathrm{mol}$ at $150{ }^{\circ} \mathrm{C}$ ) and strongly interlocked. The reaction can thus follow multiple reaction channels, a feature which is expected to be at the origin of the good kinetics of this system. Our results also point out to the active role of $\mathrm{PPh}_{3}$ ligands, which undergo significant conformational changes as the reaction occurs, and provide insights into the role of the base, which acts as a "co-catalyst" by facilitating proton transfers within active species. Activation barriers decrease on going from methanol to ethanol and isopropanol substrates, in accord with experiment.
\end{abstract}




\section{Introduction}

Generation of hydrogen from renewable resources still represents a challenging task in the larger framework of sustainable power management. Currently, hydrogen is mainly generated from fossil fuel (e.g. natural gas, liquid hydrocarbons, and coal), ${ }^{1}$ therefore releasing massive amounts of $\mathrm{CO}_{2}$ during the production process. On the other hand, an increasing interest has emerged in the use of renewable biomass and its fermentation products (i.e., mainly alcohols) as an alternative to fossil feedstocks, which allows for an almost closed carbon cycle thanks to the $\mathrm{CO}_{2}$-consuming photosynthesis reaction occurring within plants. In particular, the use of alcohols as initial substrate has stimulated an important research effort, aiming ultimately to develop efficient catalytic systems to produce hydrogen at an industrial scale. Whereas some interesting heterogeneous catalysts are being developed, ${ }^{2}$ the design of efficient homogeneous catalysts still remains at its infancy. ${ }^{3}$ Pioneering studies revealed the possibility of producing hydrogen from alcohols using Rhodium ${ }^{4}$ and Ruthenium ${ }^{5}$ precursors, and despite significant subsequent research progresses ${ }^{6}$ the obtained turnover frequencies (TOF) are generally low. The first efficient homogenous catalytic system was developed in the late 1980's by ColeHamilton et al., ${ }^{7}$ where high turnover frequencies (TOFs; up to $520 \mathrm{~h}^{-1}$ for butanol) are achieved at $150^{\circ} \mathrm{C}$ and in presence of a Ruthenium catalyst and triphenylphosphine ligands $\left(\mathrm{PPh}_{3}\right.$; see Scheme 1). Subsequent studies focused on the development of more efficient catalysts, active under milder conditions ${ }^{8}$ and free of phosphorus atoms. ${ }^{9}$



Scheme 1: Methanol dehydrogenation catalyzed by $\left[\mathrm{RuH}_{2}\left(\mathrm{H}_{2}\right)\left(\mathrm{PPh}_{3}\right)_{3}\right](\mathbf{1})$.

However, little is known on the mechanism of these reactions, since it is not easy to obtain detailed mechanistic insights from experiments. Some valuable information can be gained, however, e.g. by analyzing the initial reaction rate upon the addition of different catalyst ligands, ${ }^{10}$ or by spectroscopic characterization of selected resting states. ${ }^{11}$ However, a full elucidation of catalytic cycles, including the characterization of relevant transition states and short-life intermediates, is scarcely possible. In such a situation, computer modelling contributes profoundly to our understanding of reaction mechanisms. Density Functional 
This led us to undertake a density functional theory study on the classic Morton and ColeHamilton system, ${ }^{7 a}$ which is found to be reasonably active, and for which some experimental mechanistic information are available in the literature. The latter is based on a $\left[\mathrm{RuH}_{2}\left(\mathrm{X}_{2}\right)\left(\mathrm{PPh}_{3}\right)_{3}\right]\left(\mathrm{X}_{2}=\mathrm{N}_{2}\right.$ or $\left.\mathrm{PPh}_{3}\right)$ catalyst precursor, and the well-known Ruthenium tetrahydride complex ${ }^{11 \mathrm{~b}, 15}\left[\mathrm{RuH}_{2}\left(\mathrm{H}_{2}\right)\left(\mathrm{PPh}_{3}\right)_{3}\right]$ (1) is expected to be a key active species. Moreover, this reaction requires the presence of a base $(\mathrm{NaOH})$ and occurs at a moderately high temperature $\left(150{ }^{\circ} \mathrm{C}\right.$; see Scheme 1$)$. A preliminary mechanism has been proposed, in which all steps involve intermediates retaining their three coordinated triphenylphosphine ligands, as found in $\mathbf{1}^{7 \mathrm{a}}$ However, this system was further investigated by Shinoda et al., ${ }^{10,16}$ who found that the addition of free $\mathrm{PPh}_{3}$ ligands retards the reaction, a feature which suggests the presence of a phosphine dissociation pre-equilibrium. Moreover, the understanding of this catalytic system is complicated by the presence of side reactions, in particular alcohol decarbonylation ${ }^{17}$ which can be competitive with the dehydrogenation reaction, and can lead to catalyst deactivation upon the formation of the $\left[\mathrm{RuH}_{2}(\mathrm{CO})\left(\mathrm{PPh}_{3}\right)_{3}\right]$ complex. ${ }^{7}$

Following a computational protocol we have established recently (see Method section below), ${ }^{18}$ we first investigate the mechanism initially proposed by Morton and ColeHamilton $^{7 \mathrm{a}}$ (hereafter noted pathway A), using methanol as substrate. Next, three other possible reaction channels (pathways B-D) are proposed, guided by computational evidences (reaction free energies between intermediates and free energies of activation) and inspired by other mechanistic reports on closely related reactions found in the literature. ${ }^{19}$ Our results reveal that the studied reaction can follow multiple reaction channels, since these four mechanisms are found to be competitive and strongly interlocked, a feature which may be at 
the origin of the good kinetics of this system. The influence of the alcohol substrate on the dehydrogenation mechanism(s), the role of the base and the importance of steric effects are also investigated and discussed herein.

\section{Methods}

We have recently established a cost-effective protocol $^{18}$ allowing to compute accurate reaction free energies in solution and to consider the actual $\mathrm{PPh}_{3}$ ligands which are critically needed in order to properly account for their electronic and steric effects. Briefly, our approach is based on geometry optimizations and computation of thermochemistry corrections at a fairly low computational level, whereas refined energies are obtained using a larger basis set in conjunction with the recently developed B97-D functional. ${ }^{20}$ The latter allows to account for the critical non-covalent interactions involved in this system. ${ }^{21}$ Solvent effects are also taken into account via the use of a continuum model. In details, the following steps are involved:

Geometries and thermodynamic corrections. Geometries of complexes 1-18 were fully optimized at the RI-BP86/ECP1 level, i.e. employing the exchange and correlation functionals of Becke ${ }^{22}$ and Perdew, ${ }^{23}$ respectively, in conjunction with the SDD basis on Ru, denoting the small-core Stuttgart-Dresden relativistic effective core potential (ECP) together with its valence basis set, ${ }^{24}$ and the standard $6-31 \mathrm{G}(\mathrm{d}, \mathrm{p})$ basis for all other elements, except the $\mathrm{C}$ and $\mathrm{H}$ atoms of phenyl rings on which the smaller 3-21G basis were used, ${ }^{25}$ and suitable auxiliary basis sets for the fitting of the Coulomb potential. ${ }^{26}$ Harmonic frequencies were computed analytically and were used without scaling to obtain enthalpic and entropic corrections at the experimentally used temperature of $423 \mathrm{~K}^{7 \mathrm{a}}$ The corresponding correction terms $\delta E_{G}$ were estimated at the RI-BP86/ECP1 level and have been obtained as the difference of the reaction energy of a given step $\left(\Delta \mathrm{E}_{\mathrm{RI}-\mathrm{BP} 86 / \mathrm{ECP} 1}\right)$ and the corresponding free energy $\left(\Delta \mathrm{G}_{\mathrm{RI}-\mathrm{BP} 86 / \mathrm{ECP1}}\right)$ :

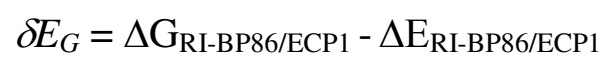

The entropic contributions have been evaluated at a pressure of 1354 atm in order to model the changes in entropy for a condensed phase. ${ }^{27}$ The corresponding correction terms $\left(\delta E_{G}\right)$ for each step of the catalytic cycles are gathered in Tables 1 and 2 along with other correction terms (vide infra). 
The initial structures of the complexes were derived from the one of $\mathbf{1 b}$, which was constructed by hand from the $\mathrm{Ru}\left(\mathrm{PPh}_{3}\right)_{3}$ moiety as found in the $\mathrm{X}$-ray structure of $\left[\mathrm{RuCl}_{2}\right.$ $\left.\left(\mathrm{PPh}_{3}\right)_{3}\right]{ }^{29}$ As tris-triphenylphosphine complexes are quite flexible, a systematic conformational search on complex $\mathbf{1 b}$ has been performed by optimizing 27 conformers obtained by rotations of the 9 phenyl rings of the ligands around their P-C bonds. The outcome of this search revealed that the most stable complex corresponds to the one where all triphenylphosphine ligands adopt propeller-like conformations, ${ }^{30}$ more or less distorted due to interactions between the positively charged phenyl hydrogens and the negatively charged hydride ligands. The other complexes have been constructed by hand, following the reaction path, i.e. starting from the structure of the previous step and keeping the conformation of the $\mathrm{PPh}_{3}$ ligands unaltered. Such procedure is therefore consistent with a reaction following a least motion pathway. Concerning $\mathrm{Ru}$ complexes possessing only two $\mathrm{PPh}_{3}$ ligands in axial position, a regular propeller conformation can be easily adopted by both ligands due to the lack of steric interaction between them. However, two conformational diastereoisomers can be obtained for theses complexes by inversion of the propeller configuration of one phosphine. The latter are therefore labelled "pp" and "pm", following the notation adopted by Davies et al. in ref ${ }^{31}$ (see Figure S1). The relative energies between the "pp" and "pm" conformers are shown to be quite small (see Table S1) and the "pm" conformers are generally found to be more stable. We therefore only considered "pm" intermediates and transition states in the investigated pathways $\mathbf{C}$ and $\mathbf{D}$ (vide infra) and the "pm" labels are omitted for clarity. 
Energies. Refined energies were obtained from single-point calculations (on the RIBP86/ECP1 geometries) using same SDD ECP was used on $\mathrm{Ru}^{24}$ and a larger basis set (hereafter noted ECP2), namely 6-311+G(d,p) on all elements excepted on all the $\mathrm{C}$ and $\mathrm{H}$ phenyl atoms where 6-31G(d,p) basis was used. The B97-D functional ${ }^{20}$ has been used in conjunction with the ECP2 basis set, as this method has been shown to lead to the most accurate binding enthalpy of $\mathrm{PPh}_{3}$ to an analogous $\mathrm{Ru}$ complex. ${ }^{18,32}$ This functional follows the DFT-D general approach of Grimme, ${ }^{20,33}$ in which the functional energies are corrected by an atomic pair-wise additive term accounting for the long-range non-covalent interactions. The corresponding interatomic $C_{6}^{i j}$ terms are calculated as the geometric mean of the standard $\mathrm{C}_{6}$ atomic coefficients. ${ }^{20}$ We note that B97-D has also been successfully employed to study a parent $\mathrm{Ru}$ catalyzed reaction. ${ }^{34}$

Energies have been corrected for the basis set superposition error (BSSE) using the counterpoise method. ${ }^{35}$ The BSSE energy corrections (noted $\delta E_{B S S E}$ ) are gathered in Table 1. Estimates of the solvation effects were computed using the Conductor-like screening model (COSMO $),{ }^{36}$ with a dielectric constant $\varepsilon=32.63$ to model the experimentally used methanol solvent. Dielectric constants of 24.55 and 20.18 have been used to model ethanol and isopropanol, respectively (see Table 2 and discussion section of the paper). Unless otherwise indicated methanol is used as solvent. We defined the $\delta E_{\text {solv }}$ energy correction as the difference between the reaction energy in the continuum $\left(\Delta \mathrm{E}_{\mathrm{COSMO}}\right)$ and in the gas phase $(\Delta \mathrm{E})$, at the B97-D/ECP2 level:

$$
\delta E_{\text {solv }}=\Delta \mathrm{E}_{\mathrm{COSMO}}-\Delta \mathrm{E}
$$

Both counterpoise and COSMO corrections were calculated by performing single-point calculations at the B97-D/ECP2 level on the BP86/ECP1 geometries. The final $\Delta \mathrm{G}$ values are calculated as a sum of all energy correction terms, added to the raw B97-D/ECP2 gas phase reaction energies $(\Delta \mathrm{E})$ :

$$
\Delta \mathrm{G}=\Delta \mathrm{E}+\delta E_{s o l v}+\delta E_{B S S E}+\delta E_{G}
$$

Where $\Delta \mathrm{E}, \delta E_{\text {solv }}$ and $\delta E_{B S S E}$ are computed at the B97-D/ECP2 level and $\delta E_{G}$ at the RIBP86/ECP1 level (vide supra). 
In order to compare the kinetics of the four investigated pathways in a consistent manner, it is necessary to overcome the ambiguity stemming from the BSSE counterpoise correction when more than one ligand is coordinated/decoordinated during a given reaction. For that purpose, the initiation energies and activation barriers have been re-computed using a more elaborated BSSE correction, and using a larger basis set (hereafter noted ECP3) where all $\mathrm{P}, \mathrm{O}, \mathrm{C}$ and $\mathrm{H}$ atoms are described by the $6-311+\mathrm{G}(\mathrm{d}, \mathrm{p})$ basis set (and the same SDD ECP on Ru). In this approach, the intermolecular BSSE for a given reaction (e.g. $R u L_{n} \mathbf{L}^{\prime} \rightarrow \operatorname{Ru} \mathbf{L}_{\mathbf{n}}+\mathbf{L}^{\prime}$ ) is estimated as a difference of the intramolecular BSSEs of the intermediates and transition states involved (i.e. RuL $\mathbf{L}_{\mathbf{n}} \mathbf{L}^{\prime}$ and $\mathrm{RuL}_{\mathbf{n}}$ ). The intramolecular BSSE (noted $\mathbf{E}_{\text {intra-BSSE}}$ ) of a given complex is estimated as the sum of counterpoise corrections associated to the dissociation of each ligand separately. The counterpoise corrections associated to hydride ligands dissociation is postulated to be 0 . For instance, for complex $\mathbf{1 b}$ :

$$
\begin{array}{rlr}
{\left[\mathrm{RuH}_{2}\left(\mathrm{H}_{2}\right)\left(\mathrm{PPh}_{3}\right)_{3}\right]} & \rightarrow\left[\mathrm{RuH}_{2}\left(\mathrm{PPh}_{3}\right)_{3}\right]+\mathrm{H}_{2} & \text { BSSE }_{\mathbf{1}} \\
{\left[\mathrm{RuH}_{2}\left(\mathrm{H}_{2}\right)\left(\mathrm{PPh}_{3}\right)_{3}\right]} & \rightarrow\left[\mathrm{RuH}_{2}\left(\mathrm{H}_{2}\right)\left(\mathrm{PPh}_{3}\right)_{2}\right]+\mathrm{PPh}_{3} \text { (equatorial) } & \text { BSSE }_{\mathbf{2}} \\
{\left[\mathrm{RuH}_{2}\left(\mathrm{H}_{2}\right)\left(\mathrm{PPh}_{3}\right)_{3}\right] \rightarrow\left[\mathrm{RuH}_{2}\left(\mathrm{H}_{2}\right)\left(\mathrm{PPh}_{3}\right)_{2}\right]+\mathrm{PPh}_{3} \text { (axial 1) }} & \text { BSSE }_{\mathbf{3}} \\
{\left[\mathrm{RuH}_{2}\left(\mathrm{H}_{2}\right)\left(\mathrm{PPh}_{3}\right)_{3}\right] \rightarrow\left[\mathrm{RuH}_{2}\left(\mathrm{H}_{2}\right)\left(\mathrm{PPh}_{3}\right)_{2}\right]+\mathrm{PPh}_{3} \text { (axial 2) }} & \text { BSSE }_{\mathbf{4}}
\end{array}
$$

and $\mathbf{E}_{\text {intra-BSSE }}(\mathbf{1 b})=\mathbf{B S S E}_{1}+\mathrm{BSSE}_{2}+\mathrm{BSSE}_{3}+\mathrm{BSSE}_{4}$.

The corresponding intermolecular correction term ( $\delta \mathrm{E}^{\prime}$ bsse $)$ e.g. for the reaction : $\mathbf{1 b} \rightarrow \mathbf{2}+\mathrm{H}_{2}$ is therefore obtained as: $\delta E_{\text {bsse }}^{\prime}=\mathbf{E}_{\text {intra-BSSE}}(\mathbf{2})-\mathbf{E}_{\text {intra-BSSE}}(\mathbf{1 b})$, where $\mathbf{E}_{\text {intra-BSSE}}(\mathbf{2})$ is computed in a similar manner considering complex 2.

The gas phase phase energies $\left(\Delta E^{E C P 3}\right)$, the corresponding solvation $\left(\delta E_{\text {solv }}{ }^{E C P 3}\right)$ and BSSE $\left(\delta E^{\prime}{ }_{B S S E}{ }^{E C P 3}\right)$ correction terms are gathered in Table 2, whereas the values of the "BSSE $\mathbf{n}_{\mathbf{n}}$ " and $\mathbf{E}_{\text {intra-BSSE }}$ terms are gathered in Table S3 in the Supplementary Information.

All the RI-BP86/ECP1 calculations were performed using the Gaussian03 program ${ }^{37}$ whereas the B97-D/ECP2 and B97-D/ECP3 calculations were performed with the Turbomole package (version 5-10). ${ }^{38}$ Structures of the complexes have been drawn with the VMD software. ${ }^{39}$ 


\begin{abstract}
Results
In this section we describe the four investigated pathways (noted A-D). For each pathway, the description of the reaction free energy profiles is followed by a description of relevant structural features of involved intermediates and transition states. Unless otherwise specified, all energies values stand for the Gibbs free energies of individual reactions $(\Delta G)$ computed at the ECP2 level of theory. The higher ECP3 level has been used to re-compute selected steps only, namely the initiation steps and the rate-limiting steps. All energy components are gathered in Table 1 (ECP2 level) and Table 2 (ECP3 level). A general schematic view of A-D is given in Figure 1, whereas individual full descriptions of each pathway are given separately, along with the corresponding free energies profiles (see Figures 2, 4, 6, and 8). Relevant structural information is provided in Figures 3, 5, 7 and 9, and characteristics of the initiation and rate-limiting steps are summarized in Tables 2 and S4.
\end{abstract}




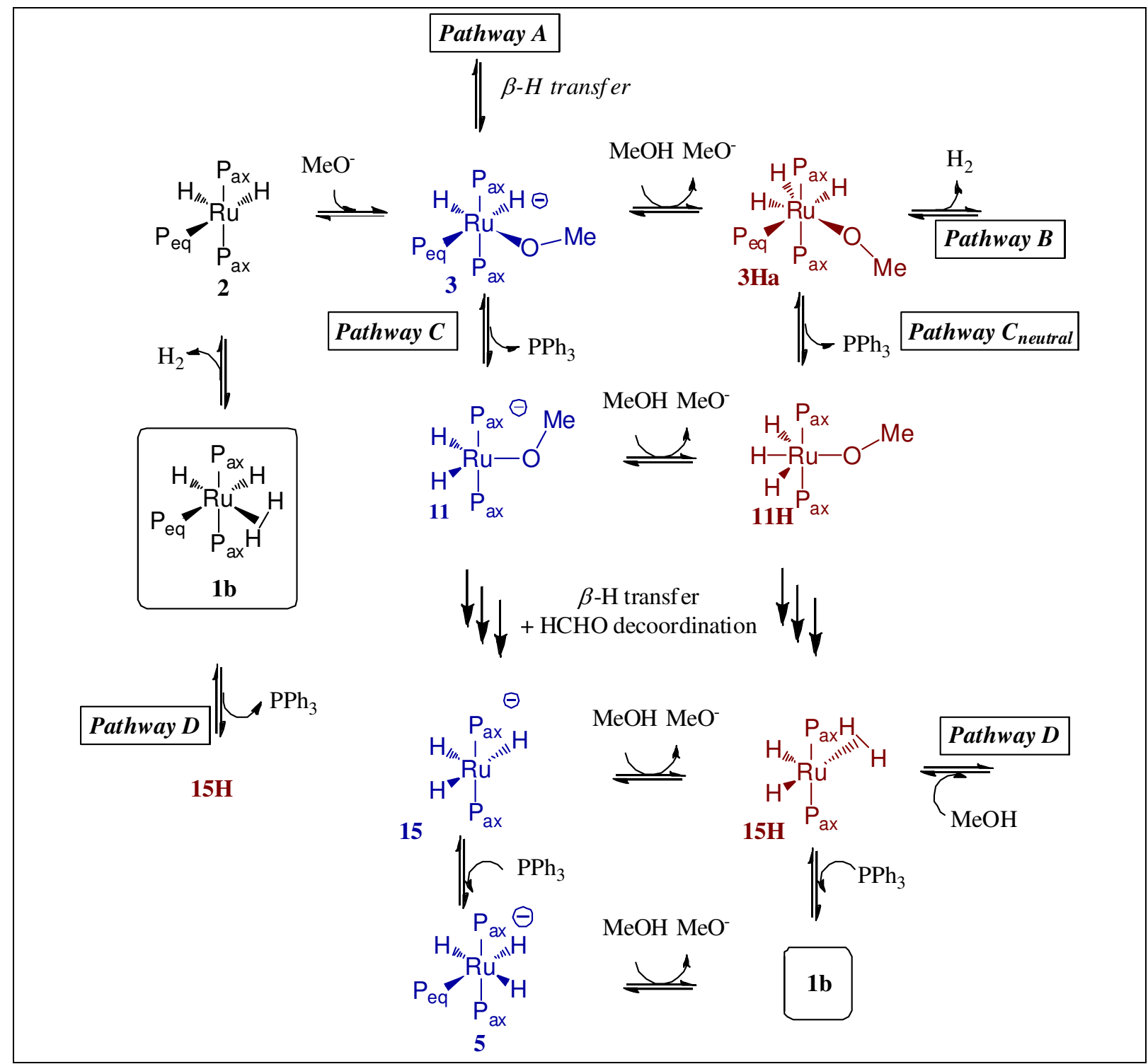

Figure 1: Overview of the investigated mechanisms A-D. " $\mathrm{P}_{\mathrm{eq}}$ " and " $\mathrm{P}_{\mathrm{ax}}$ " stand for equatorial and axial $\mathrm{PPh}_{3}$ ligands, respectively. 
Table 1: Reaction energies $(\Delta E)$, correction terms for BSSE $\left(\delta E_{B S S E}\right)$, solvation $\left(\delta E_{S o l v}\right)$ and thermochemistry $\left(\delta E_{G}\right)$, and resulting reaction free energies $(\Delta G)$ in $\mathrm{kcal} / \mathrm{mol}^{(a)}$

\begin{tabular}{|c|c|c|c|c|c|}
\hline & $\Delta \mathbf{E}$ & $\delta \mathrm{E}_{\mathrm{BSSE}}$ & $\delta \mathrm{E}_{\text {Solv }}^{b}$ & $\delta \mathbf{E}_{\mathbf{G}}$ & $\Delta \mathbf{G}$ \\
\hline Global & & & & & \\
\hline $\mathrm{MeOH} \rightarrow \mathrm{H}_{2}+\mathrm{HCHO}$ & 24.0 & 0.0 & 0.5 & -12.4 & 12.1 \\
\hline \multicolumn{6}{|l|}{ Pathway A } \\
\hline $\mathbf{1 b} \rightarrow \mathbf{2}+\mathrm{H}_{2}$ & 16.7 & -0.9 & -0.1 & -11.6 & 4.2 \\
\hline $2+\mathrm{MeO}^{-} \rightarrow \mathbf{3}$ & -51.3 & 5.3 & 42.3 & 14.7 & 11.1 \\
\hline $\mathbf{2}+\mathrm{MeOH} \rightarrow \mathbf{6}$ & -11.0 & 4.4 & 4.7 & 17.7 & 15.8 \\
\hline $\mathbf{6}+\mathrm{MeO}^{-} \rightarrow \mathbf{3}+\mathrm{MeOH}$ & -40.3 & 0.0 & 37.6 & -2.9 & -5.6 \\
\hline $3 \rightarrow 4$ & 11.5 & 0.0 & -6.1 & -1.6 & 3.8 \\
\hline $\mathbf{4} \rightarrow \mathbf{5}+\mathrm{HCHO}$ & 15.0 & -3.0 & 0.4 & -12.1 & 0.3 \\
\hline $\mathbf{5}+\mathrm{MeOH} \rightarrow \mathbf{1 b}+\mathrm{MeO}^{-}$ & 32.1 & 0.0 & -36.1 & -1.9 & -5.8 \\
\hline $1 \mathrm{~b} \rightarrow \mathrm{TS}_{1 \mathrm{~b}-2}$ & 15.5 & 0.0 & 0.3 & -6.5 & 9.4 \\
\hline $3 \rightarrow$ TS $_{3-4}$ & 24.1 & 0.0 & -7.5 & 0.1 & 16.6 \\
\hline \multicolumn{6}{|l|}{ Pathway B } \\
\hline $\mathbf{3}+\mathrm{MeOH} \rightarrow \mathbf{3 H b}+\mathrm{MeO}^{-}$ & 45.2 & 0.0 & -37.7 & 0.1 & 7.6 \\
\hline $3 \mathrm{Hb} \rightarrow 7+\mathrm{H}_{2}$ & 2.2 & -1.0 & 0.0 & -8.5 & -7.3 \\
\hline $7 \rightarrow 8$ & 4.7 & 0.0 & -1.4 & -1.1 & 2.2 \\
\hline $8 \rightarrow 9$ & -4.9 & 0.0 & 0.7 & -1.5 & -5.6 \\
\hline $9 \rightarrow 10$ & 12.6 & 0.0 & 0.8 & -1.4 & 12.0 \\
\hline $\mathbf{1 0} \rightarrow \mathbf{2}+\mathrm{HCHO}$ & 15.6 & -3.7 & -4.2 & -14.8 & -7.2 \\
\hline $\mathbf{3 H b} \rightarrow \mathrm{TS}_{3 \mathrm{Hb}-7}$ & 9.4 & 0.0 & 0.1 & 0.0 & 9.5 \\
\hline $7 \rightarrow \mathbf{T S}_{7-8}$ & 6.4 & 0.0 & -1.2 & 0.7 & 5.9 \\
\hline $8 \rightarrow$ TS $_{8-9}$ & 2.7 & 0.0 & 0.3 & -0.7 & 2.3 \\
\hline $9 \rightarrow$ TS $_{9-10}$ & 20.2 & 0.0 & 0.6 & -0.3 & 20.6 \\
\hline $2+\mathrm{MeOH} \rightarrow \mathbf{6}$ & -11.0 & 4.4 & 4.7 & 17.7 & 15.8 \\
\hline $6 \rightarrow 3 \mathrm{Hb}$ & 4.8 & 0.0 & -0.1 & -2.8 & 1.9 \\
\hline $6 \rightarrow \mathrm{TS}_{6-3 \mathrm{Hb}}$ & 17.5 & 0.0 & -0.3 & -2.9 & 14.3 \\
\hline
\end{tabular}


Table 1 continued:

\begin{tabular}{|c|c|c|c|c|c|}
\hline & $\Delta \mathbf{E}$ & $\delta \mathrm{E}_{\mathrm{BSSE}}$ & $\delta \mathrm{E}_{\text {Solv }}^{b}$ & $\delta \mathbf{E}_{\mathbf{G}}$ & $\Delta \mathbf{G}$ \\
\hline \multicolumn{6}{|l|}{ Pathway C } \\
\hline $3 \rightarrow \mathbf{1 1}+\mathrm{PPh}_{3}$ & 48.2 & -10.2 & -13.6 & -20.9 & 3.5 \\
\hline $11 \rightarrow 12$ & 3.4 & 0.0 & -0.4 & 1.5 & 4.5 \\
\hline $12 \rightarrow 13$ & -8.5 & 0.0 & -1.4 & 1.1 & -8.8 \\
\hline $13 \rightarrow 14$ & 27.0 & 0.0 & -0.9 & -5.5 & 20.6 \\
\hline $\mathbf{1 4} \rightarrow \mathbf{1 5}+\mathrm{HCHO}$ & 14.4 & -3.2 & -6.3 & -13.1 & -8.1 \\
\hline $15+\mathrm{PPh}_{3} \rightarrow \mathbf{5}$ & -58.0 & 9.2 & 16.8 & 23.3 & -8.8 \\
\hline $11 \rightarrow \mathrm{TS}_{11-12}$ & 4.9 & 0.0 & 0.3 & -0.5 & 4.6 \\
\hline $12 \rightarrow \mathrm{TS}_{12-13}$ & 1.8 & 0.0 & -0.9 & 0.0 & 0.9 \\
\hline $13 \rightarrow \mathrm{TS}_{13-14}$ & 28.5 & 0.0 & -0.7 & -5.1 & 22.7 \\
\hline \multicolumn{6}{|l|}{ Pathway D } \\
\hline $\mathbf{1 5}+\mathrm{MeOH} \rightarrow \mathbf{1 5 H}+\mathrm{MeO}^{-}$ & 24.2 & 0.0 & -24.8 & -1.5 & -2.0 \\
\hline $\mathbf{1 5 H}+\mathrm{MeOH} \rightarrow \mathbf{1 6 H b}$ & -20.1 & 3.9 & 4.7 & 15.8 & 4.3 \\
\hline $\mathbf{1 6 H b} \rightarrow \mathbf{1 7}+\mathrm{H}_{2}$ & 18.5 & -0.7 & -0.3 & -10.2 & 7.3 \\
\hline $\mathbf{1 7}+\mathrm{MeO}^{-} \rightarrow \mathbf{1 1}+\mathrm{MeOH}$ & -35.0 & 0.0 & 29.9 & -0.5 & -5.6 \\
\hline $16 \mathrm{Hb} \rightarrow \mathrm{TS}_{16 \mathrm{Hb}-17}$ & 16.9 & 0.0 & 0.3 & -8.1 & 9.1 \\
\hline
\end{tabular}

(a) B97-D/ECP2 energies. $\Delta \mathrm{G}=\Delta E+\delta E_{B S S E}+\delta E_{S o l v}+\delta E_{G}$.

(b) $\mathrm{MeOH}$ has been used as solvent. 
Table 2: Refined free energies (in $\mathrm{kcal} / \mathrm{mol}$, at the B97-D/ECP3 level) for initiation steps and overall activation barriers of pathways A-D.

\begin{tabular}{|c|c|c|c|c|c|c|}
\hline & & $\Delta \mathbf{E}$ & $\delta \mathbf{E}_{\text {BSSE }}$ & $\delta \mathbf{E}_{\text {Solv }}$ & $\delta \mathbf{E}_{\mathbf{G}}$ & $\Delta \mathbf{G}$ \\
\hline & Initiation free energies $^{(a)}$ & & & & & \\
\hline $\mathbf{B}$ & $\mathbf{1 b} \rightarrow \mathbf{2}+\mathrm{H}_{2}$ & 16.6 & -0.5 & -0.2 & -11.6 & 4.3 \\
\hline D & $1 b \rightarrow 15 H+\mathrm{PPh}_{3}$ & 46.3 & -7.0 & -5.5 & -22.9 & 10.9 \\
\hline & Overall free energy barriers & & & & & \\
\hline & Methanol $^{(a)}$ & & & & & \\
\hline $\mathbf{A}$ & $\mathbf{1 b}+\mathrm{MeO}^{-} \rightarrow \mathbf{T S}_{3-4}+\mathrm{H}_{2}$ & -15.4 & 5.0 & 36.6 & 3.2 & 29.4 \\
\hline B & $\mathbf{2}+\mathrm{MeOH} \rightarrow \mathbf{T S}_{\mathbf{3 H b}-7}$ & 5.2 & 6.9 & 5.1 & 14.9 & 32.1 \\
\hline $\mathbf{C}$ & $\mathbf{1 b}+\mathrm{MeO}^{-} \rightarrow \mathbf{T S}_{\mathbf{1 3 - 1 4}}+\mathrm{H}_{2}+\mathrm{PPh}_{3}$ & 28.2 & -5.2 & 28.6 & -20.3 & 31.3 \\
\hline $\mathbf{D}$ & $\begin{array}{l}\mathbf{1 3}+\mathbf{2} \mathrm{MeOH} \rightarrow \mathbf{T S}_{\mathbf{1 6} \mathbf{H b}-\mathbf{1 7}}+\mathrm{HCHO}+\mathrm{MeO}^{-} \\
\text {Ethanol }^{(b)}\end{array}$ & 68.4 & 0.3 & -29.4 & -12.4 & 27.0 \\
\hline $\mathbf{A}$ & $\mathbf{1 b}+\mathrm{EtO}^{-} \rightarrow \mathbf{T S}_{3-4}+\mathrm{H}_{2}$ & -13.6 & 4.3 & 33.0 & 4.3 & 28.0 \\
\hline B & $\mathbf{2}+\mathrm{EtOH} \rightarrow \mathbf{T S}_{\mathbf{3 H b}-\mathbf{7}}$ & 3.6 & 6.2 & 5.0 & 14.5 & 29.3 \\
\hline $\mathbf{C}$ & $\mathbf{1 b}+\mathrm{EtO}^{-} \rightarrow \mathbf{T S}_{13-14}+\mathrm{H}_{2}+\mathrm{PPh}_{3}$ & 25.6 & -4.9 & 26.6 & -18.6 & 28.7 \\
\hline $\mathbf{D}$ & $\begin{array}{l}\mathbf{1 3}+\mathbf{2} \mathrm{EtOH}^{\rightarrow} \mathbf{T S}_{\mathbf{1 6} \mathbf{H b}-\mathbf{1 7}}+\mathrm{MeCHO}+\mathrm{EtO}^{-} \\
\text {Isopropanol }^{(c)}\end{array}$ & 58.0 & 0.2 & -28.0 & -12.1 & 18.1 \\
\hline $\mathbf{A}$ & $\mathbf{1 b}+{ }^{i} \mathrm{PrO}^{-} \rightarrow \mathbf{T S}_{\mathbf{3}-\mathbf{4}}+\mathrm{H}_{2}$ & -11.7 & 3.9 & 31.5 & 3.8 & 27.5 \\
\hline B & $\mathbf{2}+{ }^{i} \mathrm{PrOH} \rightarrow \mathbf{T S}_{\mathbf{3 H b}-7}$ & 1.1 & 6.0 & 4.9 & 15.0 & 27.0 \\
\hline $\mathbf{C}$ & $\mathbf{1 b}+{ }^{i} \mathrm{PrO}^{-} \rightarrow \mathbf{T S}_{\mathbf{1 3 - 1 4}}+\mathrm{H}_{2}+\mathrm{PPh}_{3}$ & 27.5 & -4.7 & 24.9 & -18.4 & 29.3 \\
\hline $\mathbf{D}$ & $\mathbf{1 5 H}+{ }^{i} \mathrm{PrO}^{-} \rightarrow \mathbf{T S}_{\mathbf{1 3 - 1 4}}+\mathrm{H}_{2}$ & -18.8 & 2.3 & 30.2 & 4.4 & 18.2 \\
\hline
\end{tabular}

Model solvents: (a) $\mathrm{MeOH},(b) \mathrm{EtOH}$ and $(c){ }^{i} \mathrm{PrOH}$. 


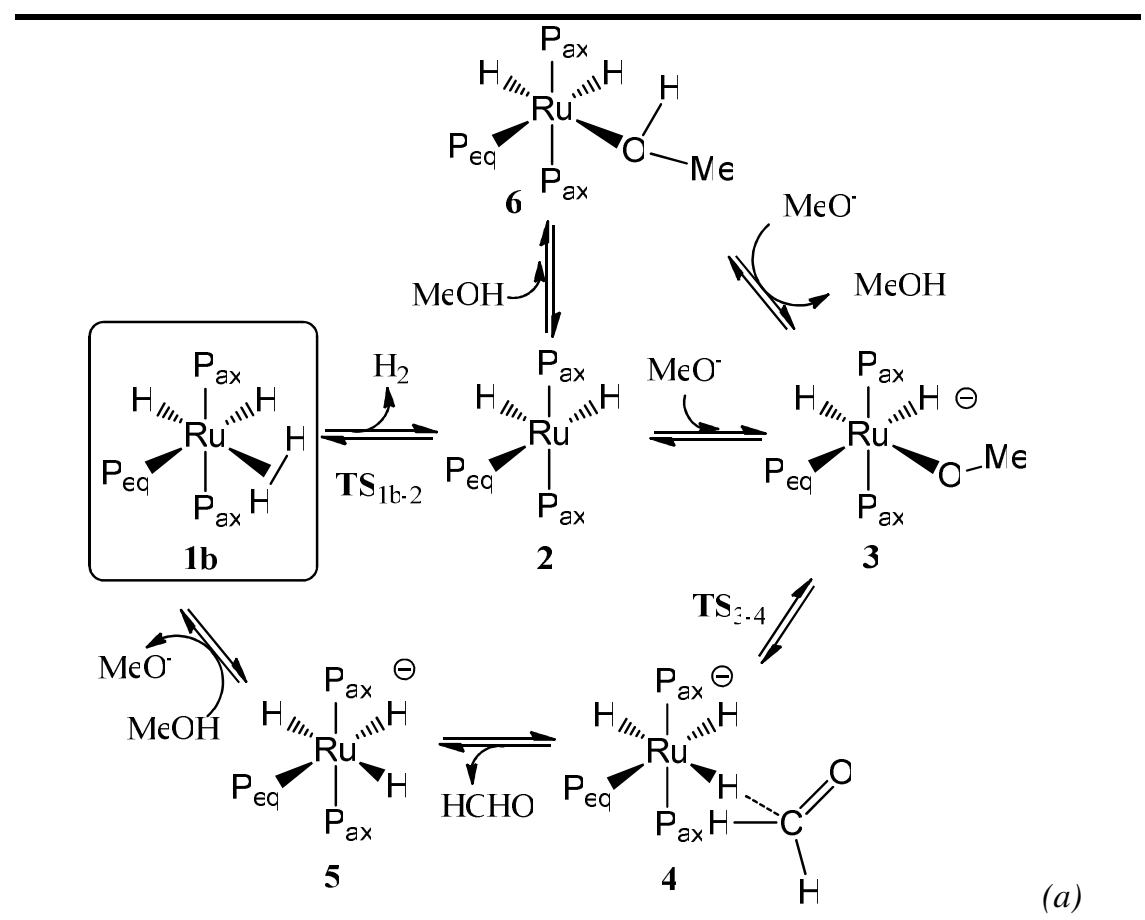

(a)
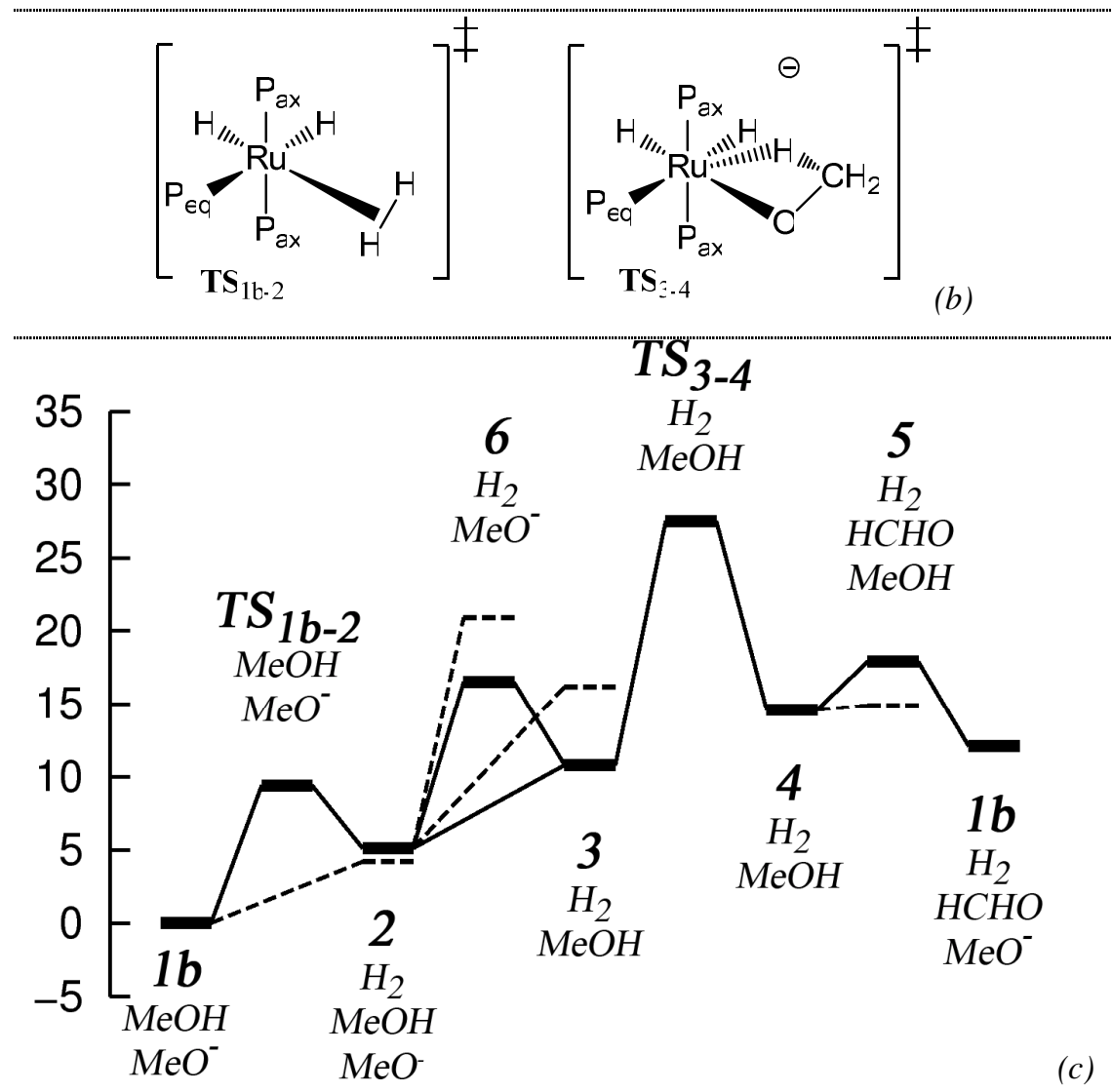

(c)

Figure 2: Reaction pathway A. (a) Catalytic cycle (b) Schematic representation of the transition states, $(\mathrm{c})$ Free energy profile $(\mathrm{kcal} / \mathrm{mol})$. Calculations at the B97-D/ECP2 level of theory using $\mathrm{MeOH}$ as model solvent. Dashed lines: BSSE corrected energies. Reaction energies are given in Table 1. 


\section{Pathway A: $\beta$-Hydride transfer occurring via a seven-coordinated transition state.}

Description of reaction pathway A. We first consider the mechanism originally proposed by Morton and Cole-Hamilton, ${ }^{7 \mathrm{a}}$ where the catalyst precursor $\left[\mathrm{RuH}_{2}\left(\mathrm{PPh}_{3}\right)_{3} \mathbf{X}\right]\left(\mathbf{X}=\mathrm{N}_{2}\right.$ or $\left.\mathrm{PPh}_{3}\right)$ affords the active catalyst $\mathbf{2}$ by decoordination of its $\mathbf{X}$ moiety (Figure 2). As the dehydrogenation reaction occurs under basic conditions, 2 can further coordinate either $\mathrm{MeO}^{-}$ (to afford 3) or a solvent molecule (to afford 6). Despite significantly attractive energies in the gas phase, both additions reactions are found to be unfavorable thermodynamically (by 11.1 and $15.8 \mathrm{kcal} / \mathrm{mol}$ for $\mathbf{3}$ and $\mathbf{6}$, respectively) due to solvation effects (mainly stemming from the desolvation of the substrate) and entropic penalties. No transition state could be located for these two addition steps. ${ }^{40}$ The intermediate $\mathbf{6}$ can be further deprotonated to afford $\mathbf{3}$. The next step consists of the transfer of one $\beta$-hydrogen of the coordinated substrate to the metal, to afford intermediate $\mathbf{4}$ where the HCHO product is "hydrogen-bonded" to the $\left[\mathrm{RuH}_{3}\left(\mathrm{PPh}_{3}\right)_{3}\right]^{-}$complex 5. ${ }^{41}$ We note that this step is particularly difficult, since it is an uphill process $(3.8 \mathrm{kcal} / \mathrm{mol})$ and a significant energy barrier has to be overcome $(16.6 \mathrm{kcal} / \mathrm{mol})$. The subsequent release of the aldehyde product is favored by entropy and is easily achieved $(+0.3 \mathrm{kcal} / \mathrm{mol})$. As reported by Halpern et al. ${ }^{11 \mathrm{c}, 11 \mathrm{~d}}$ and Cole-Hamilton et al., ${ }^{7 \mathrm{a}} \mathbf{5}$ is easily protonated (by $-5.8 \mathrm{kcal} / \mathrm{mol}$ ) to afford complex 1 .

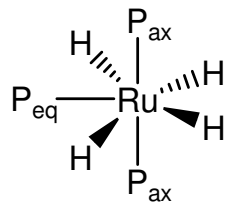

$1 \mathbf{a}$

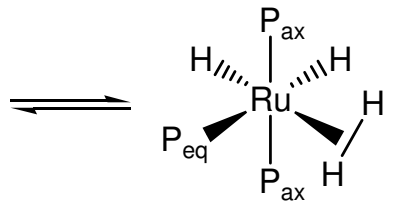

1b

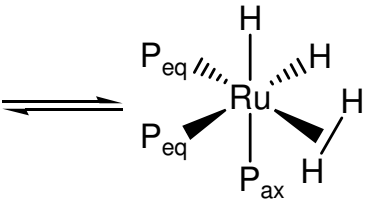

1b'

Scheme 2: Labeling of the different isomers, using complex 1 as example.

This complex can exist in two tautomeric forms, a classical tetrahydride 1a and a nonclassical dihydride 1b with $\eta^{2}$-coordinated molecular hydrogen (see Scheme 2). Both have been suggested to co-exist in a dynamic equilibrium in solution. ${ }^{1 \mathrm{~b}}$ Our calculations show that 1b is slightly more stable than $\mathbf{1 a}$ (by $3.8 \mathrm{kcal} / \mathrm{mol}$ ), consistent with these observations. We also note that complex $\mathbf{5}$ (resulting from the hydrogen transfer in $\mathbf{3}$ ) is formed as mer-isomer, whereas a $f a c$ - isomer 5 , is found in the solid state ${ }^{42}$ and by ${ }^{1} \mathrm{H}$ NMR in THF (with $\mathrm{K}^{+}$ counterions). ${ }^{11 \mathrm{a}}$ Our calculations show that $\mathbf{5}^{\prime}$ is more stable than pristine $\mathbf{5}$ by $6.9 \mathrm{kcal} / \mathrm{mol}$, 
and are therefore consistent with experiment. We also investigated the fac-isomers of $\mathbf{1 b}, \mathbf{3}$ and $\mathbf{T S}_{\mathbf{3 - 4}}$ (noted $\mathbf{1 b}, \mathbf{3}^{\prime}$ and $\mathbf{T S} \mathbf{S}_{\mathbf{3 - 4}}$ respectively) and we found that the $\mathrm{mer}$ - forms are more stable for these two complexes (by 5.4, 2.7 and $17.9 \mathrm{kcal} / \mathrm{mol}$, respectively), whereas no $f a c$ isomer could be located for $\mathbf{2}$. Thus, the steps on pathway A preceding the rate-limiting one only involve mer- isomers as shown in Figure 2.

The release of the $\mathrm{H}_{2}$ product from $\mathbf{1 b}$ is unfavorable, for both thermodynamic and kinetic reasons, since this process is $4.2 \mathrm{kcal} / \mathrm{mol}$ uphill with a $9.4 \mathrm{kcal} / \mathrm{mol}$ free energy barrier. Such a one-step reaction with a small activation barrier is consistent with the qualitative results of Linn and Halpern, ${ }^{11 \mathrm{~d}}$ who investigated the dissociation of $\mathrm{H}_{2}$ from $\mathbf{1 b}$ by exchange with $\mathrm{D}_{2}$. They found that this process is fast and complete (at $85^{\circ} \mathrm{C}$ ), and that it does not involve $\mathrm{PPh}_{3}$ dissociation. We find that $\mathbf{1 b}$ is the resting state of the system, as characterized by ${ }^{1} \mathrm{H}$ and ${ }^{31} \mathrm{P}$ NMR in non-catalytic conditions. ${ }^{11 \mathrm{~b}, 11 \mathrm{~d}}$ On this path, the rate limiting step is found to be the hydrogen transfer $(\mathbf{3} \rightarrow \mathbf{5})$, and not the $\mathrm{H}_{2}$ dissociation $(\mathbf{1 b} \rightarrow \mathbf{2})$ as initially suggested by Morton and Cole-Hamilton. ${ }^{7 \mathrm{a}}$ Computations at the higher ECP3 level show that the overall activation energy for this pathway is $29.4 \mathrm{kcal} / \mathrm{mol}$ (see Table 2). This barrier is significant, but should be surmountable at the elevated temperatures of the experiments. ${ }^{43}$

Structural features. Transition states $\mathbf{T S} \mathbf{S}_{\mathbf{1 b}-\mathbf{2}}$ and $\mathbf{T S} \mathbf{S}_{\mathbf{3}-\mathbf{4}}$ are depicted in Figure 3. In $\mathbf{T} \mathbf{S}_{\mathbf{1 b - 2}}, \mathrm{H}_{2}$ is fully decoordinated from the metal (the corresponding average $\mathrm{Ru}-\mathrm{H}_{(\mathrm{H} 2)}$ distance being ca. $3.40 \AA$ whereas the latter is ca. $1.75 \AA$ in $\mathbf{1 b}$ ). As showed by the superimposed views of the structures of $\mathbf{1 b}$ and $\mathbf{T S}_{\mathbf{1 b - 2}}$ (see Figure S2; left picture), the conformation of the ligands are very similar in these two complexes. This feature contrasts with the structure of $\mathbf{2}$, where an important reorganization of the ligands is observed, mainly via rotations of the phenyl rings around the P-C bonds (see Figure S2; right picture). Interestingly, the deformation energies in $\mathbf{1 b}$ and $\mathbf{T S}_{\mathbf{1 b - 2}}$, relatively to $\mathbf{2}$, are found to be 4.1 and $1.3 \mathrm{kcal} / \mathrm{mol}$, respectively, ${ }^{44}$ which is consistent with a gradual relaxation of the ligands as the $\mathrm{H}_{2}$ dissociation occurs. This feature therefore suggests that the presence of a barrier for this step is due the presence of the bulky $\mathrm{PPh}_{3}$ ligands. This finding is confirmed by repeating the transition state search using $\mathrm{PH}_{3}$ and $\mathrm{PMe}_{3}$ instead of $\mathrm{PPh}_{3}$ as ligands, where no transition states can be found for the $\mathrm{H}_{2}$ elimination from both $\mathbf{1 b} / \mathbf{P H}_{3}$ and $\mathbf{1 b} / \mathbf{P M e}_{3}$ analogues. 


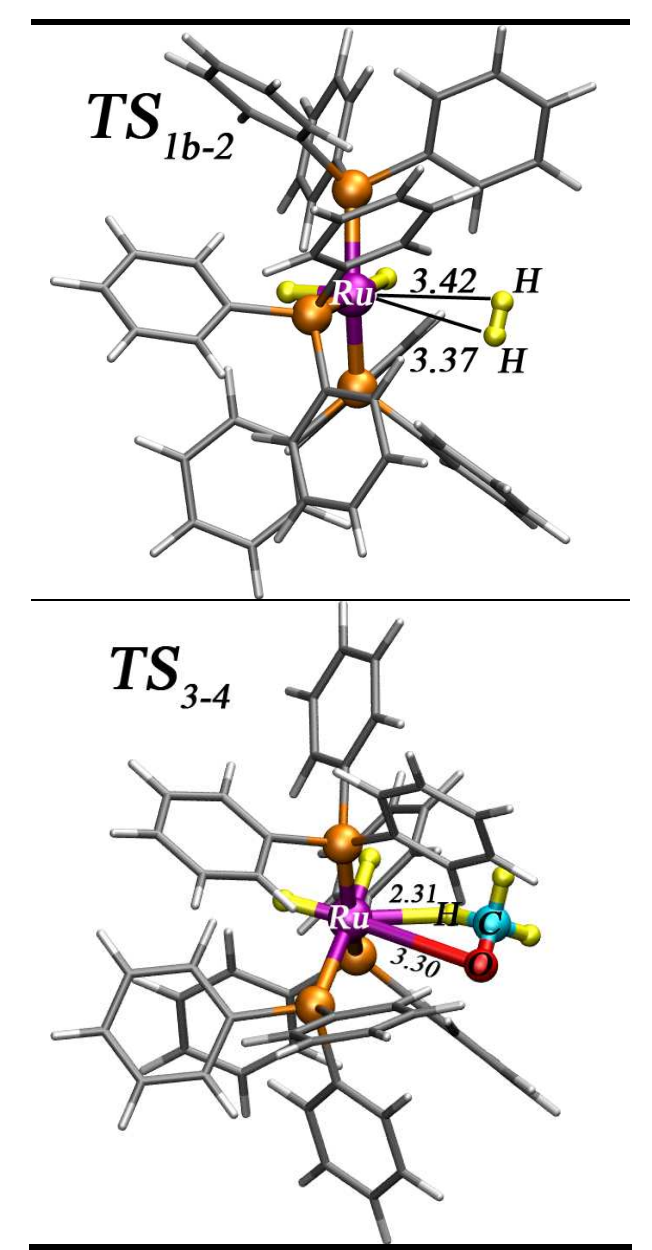

Figure 3: Transition states $\overline{\mathbf{T S}} \overline{\mathbf{S}_{\mathbf{1 b - 2}} \text { and } \mathbf{T} \mathbf{S}_{\mathbf{3}-4} \text { involved in pathway }} \mathbf{A}$ with selected interatomic distances (in $\AA$ ).

In $\mathbf{T S}_{3-4}$, the Ru-O and the Ru-H distances are significantly elongated compared to the ones observed in the linking intermediates $\mathbf{3}$ and $\mathbf{4}$ (the Ru-O distances are $3.30 \AA$ and $2.25 \AA$, in $\mathbf{T S}_{\mathbf{3 - 4}}$ and in 3, respectively, and the $\mathrm{Ru}-\mathrm{H}_{(\mathrm{Me})}$ distances are $2.31 \AA$ and $1.83 \AA$, in $\mathbf{T} \mathbf{S}_{\mathbf{3 - 4}}$ and $\mathbf{4}$, respectively). Moreover, both $\mathrm{O}$ and $\mathrm{H}$ atoms are bent out of the equatorial plane, which is typical for such highly coordinated complexes. These structural characteristics are consistent with the corresponding high energy barrier, the $\beta$-hydride transfer being hindered by the lack of room in the equatorial plane. A concerted $\mathrm{Ru}-\mathrm{O}$ bond breaking along with the formation of the $\mathrm{Ru}-\mathrm{H}$ bond occurs at a single coordination site, therefore requiring a partial decoordination of $\mathrm{MeO}^{-}$in $\mathbf{T S}_{\mathbf{3}-4}$ and the formation of a highly strained four-membered ring. All these features are particularly demanding energetically. 


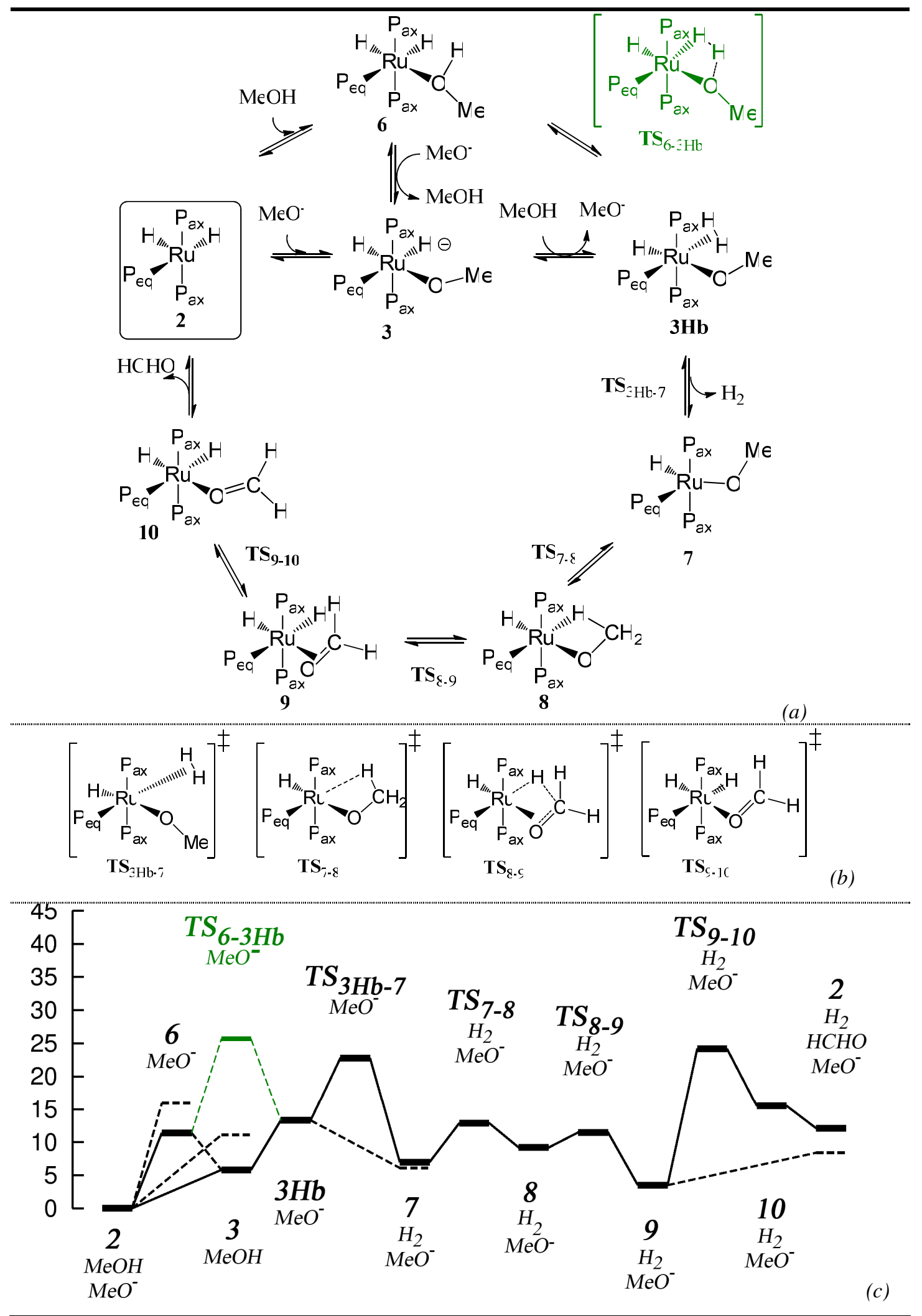

Figure 4: Reaction pathway B. See Figure 2 for a definition of labels $(a),(b),(c)$. 


\section{Pathway $B: \mathbf{H}_{2}$ elimination as a prerequisite to the $\beta$-H transfer.}

Description of reaction pathway B. Searching for more favorable pathways, we first explored the possibility that a $\mathrm{H}_{2}$ elimination occurs before the $\beta$-H transfer step. This leads to a competitive pathway $\mathbf{B}$, deriving from pathway $\mathbf{A}$ (see Figure 1), where $\mathbf{3}$ is protonated to afford 3H, from which an $\mathrm{H}_{2}$ elimination can occur (see Figure 4). As for complex 1, the resulting $\mathbf{3 H}$ complex can exist as a hepta-coordinated classical hydride isomer (3Ha) or as a hexacoordinated $\eta^{2}-\mathrm{H}_{2}$ isomer $(\mathbf{3 H b})$. We found that $\mathbf{3 H a}$ is more stable than $\mathbf{3 H b}$ by 4.1 $\mathrm{kcal} / \mathrm{mol}$, however, the latter is more likely to further undergo a $\mathrm{H}_{2}$ decoordination to afford 7 , therefore following a least motion pathway. The release of $\mathrm{H}_{2}$ is thermodynamically favorable $(-7.3 \mathrm{kcal} / \mathrm{mol})$ but a $9.5 \mathrm{kcal} / \mathrm{mol}$ barrier has to be overcome. The resulting complex 7 possesses a vacant site, where the subsequent $\beta$-H transfer can take place. The latter is achieved in two steps: ( $i$ ) first, an agostic interaction is formed between the metal and one of the three methoxy hydrogens (intermediate $8 ;+2.2 \mathrm{kcal} / \mathrm{mol}$ ), and (ii) subsequently, the latter hydrogen fully coordinates to $\mathrm{Ru}$ to form $\mathbf{9}$, where the aldehyde product is $\pi$-coordinated to the metal $(-5.6 \mathrm{kcal} / \mathrm{mol})$. Both steps possess small activation barriers of 5.9 and $2.3 \mathrm{kcal} / \mathrm{mol}$, respectively, therefore indicating that the hydrogen transfer is indeed significantly more facile than in pathway $\mathbf{A}$. The HCHO product is only weakly bonded to $\mathrm{Ru}\left(\Delta \mathrm{G}_{9 \rightarrow 2}=4.8 \mathrm{kcal} / \mathrm{mol}\right)$, but its decoordination is found to be very demanding kinetically. A potential energy surface scan along the $\mathrm{Ru}-\mathrm{C}_{\mathrm{HCHO}}$ distance revealed that this process occurs in two steps, as the aldehyde is found to move from a $\eta^{2}$ to a $\eta^{1}$ coordination mode before full decoordination can occur. The first step $(\mathbf{9} \rightarrow \mathbf{1 0})$ involves a high free energy barrier $\left(\Delta \mathrm{G}^{\ddagger}=20.6 \mathrm{kcal} / \mathrm{mol}\right)$, whereas no transition states could be located for the subsequent full dissociation of the product $(\mathbf{1 0} \rightarrow 2+\mathrm{HCHO}) .{ }^{40}$ We note that the $\mathbf{T S}_{9-10}$ and $\mathbf{T S}_{\mathbf{3 H b}-\mathbf{7}}$ transition states are both very high in energy on the reaction profile and are almost isoenergetic. Computations at the higher B97-D/ECP3 level allowed to identify the highest step and revealed that $\mathrm{H}_{2}$ dissociation is rate-limiting, with a corresponding barrier of $32.1 \mathrm{kcal} / \mathrm{mol}$ (see Table 2). Because $\mathrm{H}_{2}$ elimination occurs at a different stage compared to path $\mathbf{A}$, complex $\mathbf{1 b}$ is bypassed in path $\mathbf{B}$, where $\mathbf{2}$ would be the resting state. This pathway therefore requires an initiation step, consisting in the decoordination of $\mathrm{H}_{2}$ from $\mathbf{1 b}$ to afford $\mathbf{2}(\Delta \mathrm{G}=4.3 \mathrm{kcal} / \mathrm{mol}$, see Table 2). 
We note that in this pathway, the base is only required for the $\mathbf{2} \rightarrow \mathbf{3 H b}$ step and is not involved in any other steps. Interestingly, $\mathbf{3 H b}$ can alternatively be formed directly by intramolecular proton transfer from $\mathbf{6}\left(\Delta \mathrm{G}_{\mathbf{6}} \rightarrow \mathbf{3} \mathbf{H b}=1.9 \mathrm{kcal} / \mathrm{mol}\right)$. However, a significant activation barrier of $14.3 \mathrm{kcal} / \mathrm{mol}$ is associated to this process (see green line in Figure 4).

Structural features. A detailed analysis of the structures of the complexes involved in this pathway reveals some interesting features (Figure 5). As observed in Pathway $\mathbf{A}$, the $\mathrm{PPh}_{3}$ ligands play an important role in the $\mathrm{H}_{2}$ dissociation step, which is the rate-limiting step of this pathway. It is noteworthy that the deformation energies in $\mathbf{3} \mathbf{H b}$ and $\mathbf{T S}_{\mathbf{3 H b} \mathbf{7}}$ are significantly higher here (18.8 and $7.8 \mathrm{kcal} / \mathrm{mol}$, respectively), ${ }^{44}$ and almost fully balances the loss of the $\mathrm{H}_{2}$ binding energy. Superimposed structures of $\mathbf{3 H b}$ and $\mathbf{7}$ effectively reveal some reorganization of the $\mathrm{PPh}_{3}$ ligands, via rotation of the phenyl rings, as observed above (see Figure S2). This can also be seen on the potential energy profile for the dissociation of $\mathrm{H}_{2}$, where a quick drop in energy is observed when the $\mathrm{Ru}-\mathrm{H}_{\mathrm{H} 2}$ distance reaches $c a .3 \AA$ (see Figure S3). Looking at the structures of the involved complexes shows that, in $\mathbf{3 H b}$ and $\mathbf{T S}_{\mathbf{3 H b}-7}$, one $\mathrm{PPh}_{3}$ ligand is somewhat distorted with one phenyl ring almost parallel to the equatorial plane. This contrasts with 7 , in which all $\mathrm{PPh}_{3}$ ligands adopt a regular propeller conformation. We note that repeating this calculation with $\mathrm{PH}_{3}$ as ligand leads to a nonactivated process (see Figure S3). However, the rearrangement of the $\mathrm{PPh}_{3}$ ligands is not the only origin of the important deformation energy involved in this process, since an important reorganization of the $\mathrm{Ru}$ coordination sphere itself is also observed: In $\mathbf{3 H b}$, the $\mathrm{Ru}$ center possesses quasi-octahedral environment, where the $<\mathrm{P}_{\mathrm{eq}}-\mathrm{Ru}-\mathrm{O}>$ angle is $83.6^{\circ}$ (see Figure S3) and where the $\mathrm{O}_{\text {methoxy }}$ and $\mathrm{C}_{\text {methoxy }}$ atoms are in the equatorial plane $\left(<\mathrm{P}_{\text {eq }}-\mathrm{Ru}-\mathrm{O}-\mathrm{C}>=\right.$ $163.2^{\circ}$ ). As the decoordination of $\mathrm{H}_{2}$ occurs, the $\left\langle\mathrm{P}_{\mathrm{eq}}-\mathrm{Ru}-\mathrm{O}\right\rangle$ angle tends to increase, indicating that the $\mathrm{Ru}$ center moves towards a trigonal bipyramidal environment. Following the value of this angle along the IRC reveals that the latter is ca. $100^{\circ}$ in $\mathbf{T S}_{\mathbf{3 H b}-\mathbf{7}}, 115^{\circ}$ in 7.... $\mathrm{H}_{2}$ (i.e. a complex where $\mathrm{H}_{2}$ is all but decoordinated) and ca. $132^{\circ}$ in 7 (where $\mathrm{H}_{2}$ is removed completely). At the same time, the methoxy ligand rotates from a fully equatorial orientation towards a perpendicular orientation $\left(\left\langle P_{e q}-R u-O-C\right\rangle=163^{\circ}\right.$ in $\mathbf{3 H b}$ and $84^{\circ}$ in 7 ; see Figure S3). Interestingly, no stationary point could be located for a conformer of $\mathbf{3 H b}$ in which the methoxy ligand would be perpendicular to the equatorial plane, certainly due to steric repulsions with the bulky $\mathrm{PPh}_{3}$ ligands within the complex. 


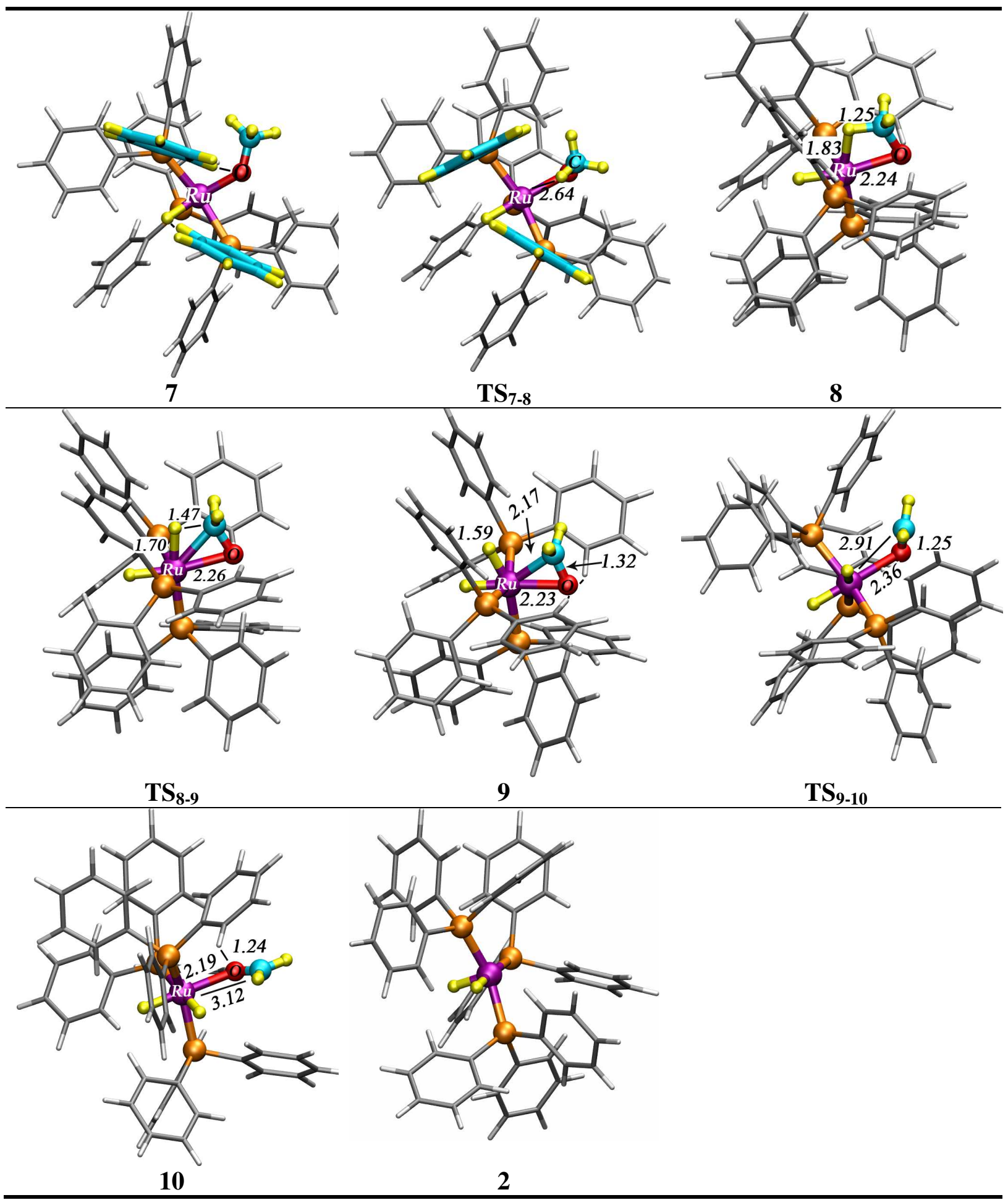

Figure 5: Structures of the intermediates and transitions states involved during the proton transfer $(\mathbf{7} \rightarrow \mathbf{9})$ and the HCHO product decoordination $(\mathbf{9} \rightarrow \mathbf{2})$ occurring in pathway $\mathbf{B}$. Selected inter-atomic distances are given in $\AA$.

The $\mathrm{PPh}_{3}$ ligands also play an important role in the $\beta-\mathrm{H}$ transfer step. In 7 , the three hydrogens of the perpendicular methoxy ligand point away from the metal center (the closest hydrogen is found at $3.27 \AA$ from $\mathrm{Ru}$ ), and the vacant coordination site is somewhat 
"shielded" by the phenyl rings of the two axial phosphine ligands (Figure 5). Interstingly, the phenyl hydrogens do not form any agostic interactions with the metal but interact with the negatively charged $\mathrm{H}_{\text {hydrid }}$ and $\mathrm{O}_{\text {methoxy }}$ atoms. A conformational reorganization of the ligands is therefore mandatory in order to afford $\mathbf{8}$, a feature which should increase the height of the corresponding activation barrier. In $\mathbf{T S}_{\mathbf{7 - 8}}$, one phenyl ring is indeed rotated in order to allow the approach of the methoxy hydrogen, which is found at $2.64 \AA$ from $\mathrm{Ru}$. The intermediate 8 is rather high in energy due to the formation of a strained four-membered ring (Ru-O-C-H), where the Ru-O-C, O-C-H and Ru-H-C angles are, respectively, 79, 116 and 100 degrees and the $\mathrm{Ru}-\mathrm{H}$ distance is $1.83 \AA$. The transfer of $\mathrm{H}$ to the metal is achieved via transition state TS 8 -9, which is similar to 8 but with an elongated $\mathrm{C}-\mathrm{H}$ distance $(1.47 \AA)$ and a shorter $\mathrm{Ru}-\mathrm{H}$ distance $(1.70 \AA)$. In 9, the transferred hydrogen is fully coordinated to the metal $(1.59 \AA)$ and the $\mathrm{C}=\mathrm{O}$ bond of the aldehyde product is strictly positioned in the equatorial plane. As observed for $\mathrm{MeO}^{-}$complexes, electrostatic interactions are formed between the oxygen atom and the phenyl hydrogens of the phosphine ligands, a feature which should slightly stabilize the bonding of the product. In $\mathbf{9}, \mathrm{HCHO}$ is $\pi$-coordinated to $\mathrm{Ru}$ and the corresponding $\mathrm{Ru}-\mathrm{C}$ and $\mathrm{Ru}-\mathrm{O}$ distances are $2.17 \AA$ and $2.23 \AA$, respectively. We note that the $\mathrm{C}=\mathrm{O}$ distance is significantly longer $(1.32 \AA)$ in 9 than in the free formaldehyde molecule $(1.22 \mathrm{~A})$, which suggests significant back-bonding interaction with the metal. As the decoordination occurs, the Ru-C distance gradually increases $\left(2.91 \AA\right.$ in $\mathbf{T S}_{\mathbf{9 - 1 0}}$ and $3.12 \AA$ in $\left.\mathbf{1 0}\right)$ and the HCHO moiety rotates from a "side-on" orientation in 9 to an equatorial "end-on" orientation in 10, where one $\mathrm{H}_{\mathrm{HCHO}}$ atom points towards an hydride ligand of the complex. We note that in $\mathbf{T S}_{9}$ 10 and 10, the $\mathrm{C}=\mathrm{O}$ distance (ca. $1.25 \AA$ ) is close to the one of the free HCHO molecule, consistent with loss of metal-ligand back-bonding. After the full dissociation of the aldehyde, the resulting complex 2 retains its pseudo-octahedral geometry, the vacant site being shielded by $\mathrm{PPh}_{3}$ phenyl rings. 


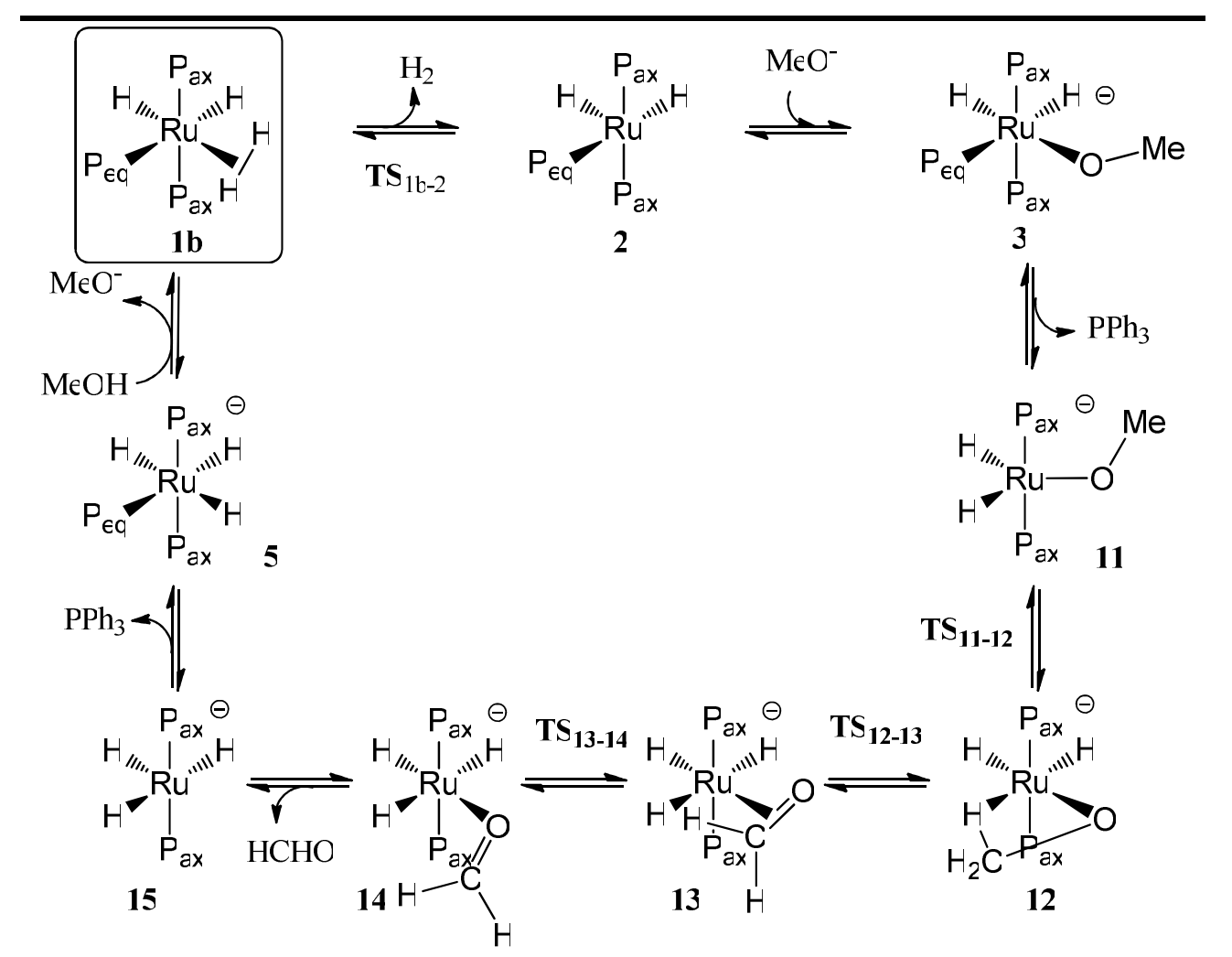

(a)

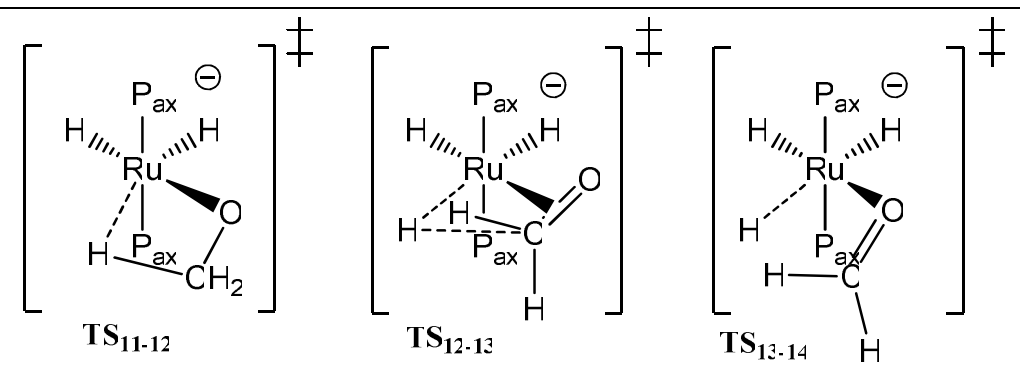

(b)

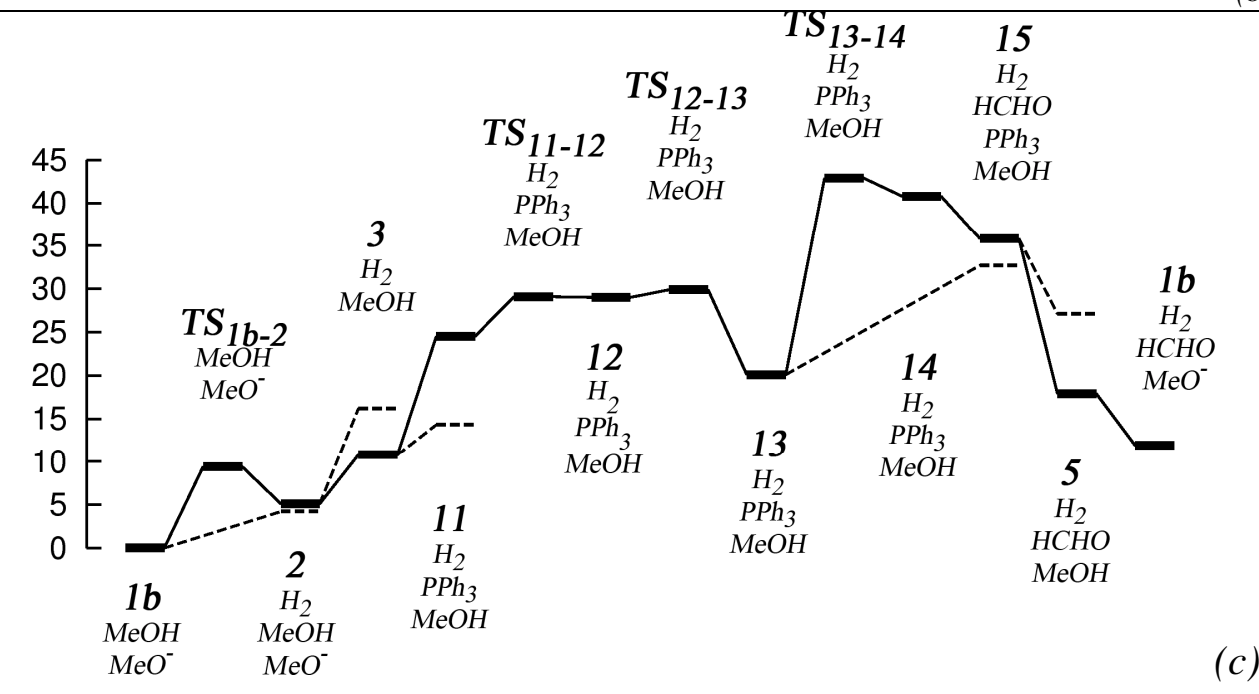

Figure 6: Reaction pathway C. See Figure 2 for a definition of labels $(a),(b),(c)$. 


\section{Pathway C : Decoordination/recoordination of one phosphine ligand.}

Description of reaction pathway $C$. Keeping in mind that the presence of a vacant site can significantly facilitate the H-transfer step (see Pathway B), one can imagine another possibility to form such a 16 electron complex by considering the decoordination of one phosphine ligand from 3 to afford 11 (Figure 6). Our calculations reveal that the $\mathrm{PPh}_{3}$ ligands are indeed weakly bonded to the metal (by $2.8 \mathrm{kcal} / \mathrm{mol}$ for an axial phosphine and by 3.5 for the equatorial one), and therefore a non negligible concentration of $\mathbf{1 1}$ should be present in the catalytic system. ${ }^{40}$ As in pathway $\mathbf{B}$, the subsequent H-transfer is achieved in two steps: first, an agostic interaction is formed between one $\mathrm{MeO}^{-}$hydrogen and the metal (intermediate 12; $\Delta \mathrm{G}=4.5 \mathrm{kcal} / \mathrm{mol}$ and $\Delta \mathrm{G}^{\ddagger}=4.6 \mathrm{kcal} / \mathrm{mol}$ ), followed by the breaking of the $\mathrm{C}-\mathrm{H}$ bond and the full coordination of the hydrogen to the metal (intermediate $13 ; \Delta \mathrm{G}=-8.8 \mathrm{kcal} / \mathrm{mol}$ and $\left.\Delta \mathrm{G}^{\ddagger}=0.9 \mathrm{kcal} / \mathrm{mol}\right)$, the HCHO product being $\pi$-coordinated to $\mathrm{Ru}$. The resulting complex 13 is quite low in energy and the subsequent decoordination of the aldehyde ligand is very demanding kinetically and thermodynamically $\left(\Delta \mathrm{G}_{13 \rightarrow 15}=12.5 \mathrm{kcal} / \mathrm{mol}\right.$ and $\Delta \mathrm{G}_{13 \rightarrow \mathrm{TS} 13-14}=$ $22.7 \mathrm{kcal} / \mathrm{mol}$ ). As observed in pathway $\mathbf{B}$, the decoordination of the product occurs via an intermediate where HCHO is $\eta^{1}$-coordinated (14), and the latter is $20.6 \mathrm{kcal} / \mathrm{mol}$ higher in free energy than 13. The last steps of the mechanism are downhill processes and consist of the recoordination of the $\mathrm{PPh}_{3}$ ligand to $\mathbf{1 5}(-8.8 \mathrm{kcal} / \mathrm{mol})$ to afford 5, which is further protonated to regenerate the active species $\mathbf{1 b}(\Delta \mathrm{G}=-5.8 \mathrm{kcal} / \mathrm{mol})$.

The rate-limiting step is clearly the decoordination of HCHO and more specifically the $\eta^{2}-\eta^{1}$ slippage involved in this process. The overall activation energy obtained at the higher ECP3 level is found to be $31.3 \mathrm{kcal} / \mathrm{mol}$ (see Table 2), therefore in the same order of magnitude as the two previously described pathways. 


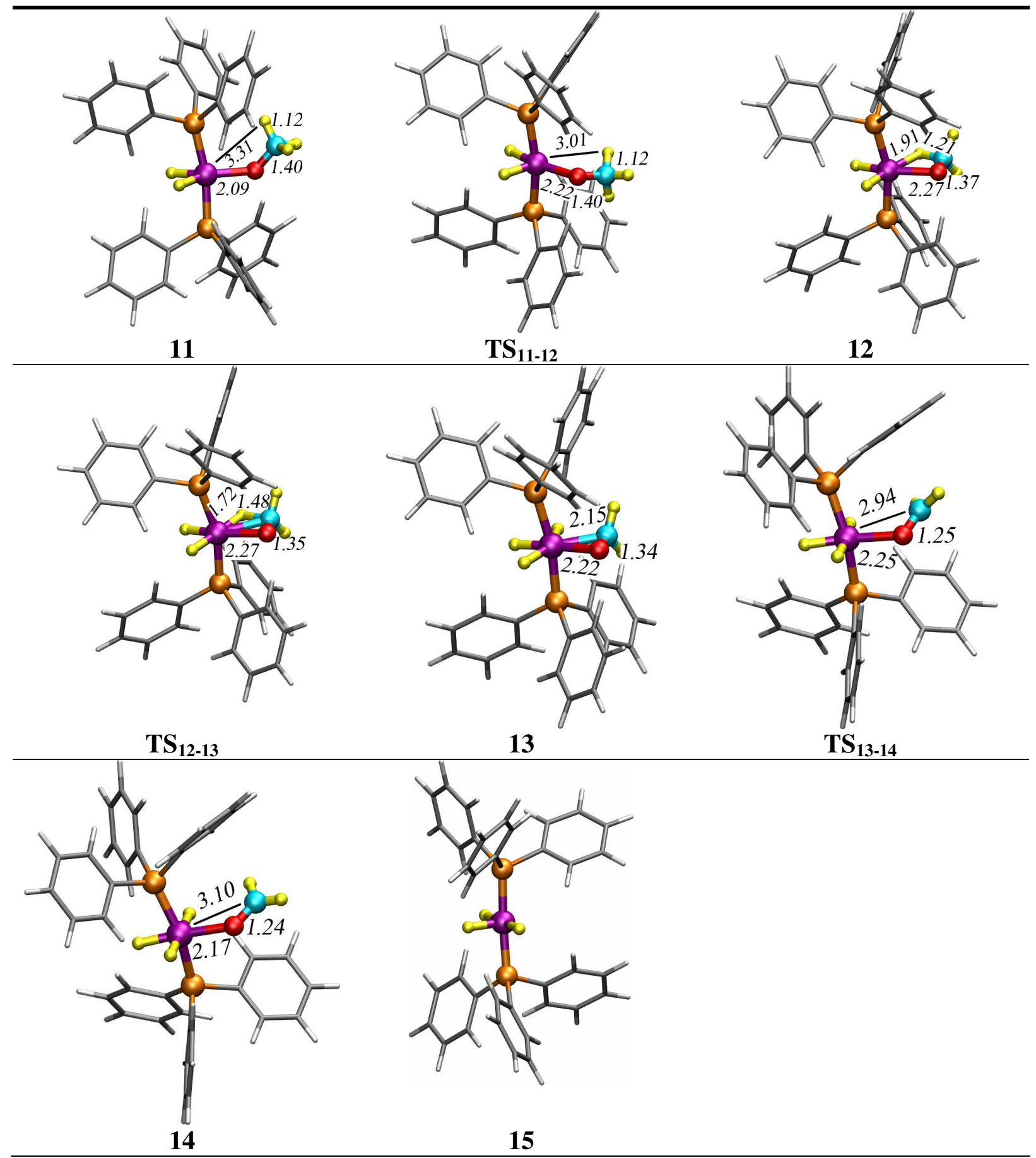

Figure 7: Structures of the intermediates and transitions states involved during the proton transfer $(\mathbf{1 1} \rightarrow 13)$ and aldehyde decoordination $(\mathbf{1 3} \rightarrow 15)$ occurring in pathway $\mathbf{C}$. Selected inter-atomic distances are given in $\AA$.

Structural features. Interestingly, the lowest minimum obtained for 11 exhibits a trigonal bypyramidal geometry where the terminal methyl group points away from the metal center, forming a $90^{\circ} \mathrm{H}_{\text {hydrid }}-\mathrm{Ru}-\mathrm{O}-\mathrm{C}$ dihedral angle (i.e., $\mathrm{Ru}, \mathrm{P}_{1}, \mathrm{P}_{2}, \mathrm{O}_{\text {methoxy }}$ and $\mathrm{C}_{\text {methoxy }}$ are in the same plane). The closest $\mathrm{H}_{-\mathrm{CH} 3}$ atom is at a $3.31 \AA$ distance from $\mathrm{Ru}$ (Figure 7). The proton transfer step therefore first requires the rotation of the methoxy ligand. A scan along the P- 
Alternative mechanisms based on $\boldsymbol{C}$. We note that the protonation reaction (i.e. $\mathbf{5}+\mathrm{MeOH} \rightarrow$ $\mathbf{1 b}+\mathrm{MeO}^{-}$) can occur at any step on the pathway between complexes 11 to $\mathbf{1 5}$, affording the protonated analogues $\mathbf{1 1 H}$ to $\mathbf{1 5 H}$ (see the two parallel pathways $\mathbf{C}$ in Figure 1). We therefore characterized another variant of pathway $\mathbf{C}$, denoted pathway " $\mathbf{C}_{\text {neutral }}$ ", where the protonation occurs at the very first step and which therefore involves neutral intermediates during the proton-transfer process (instead of occurring at the last step; see Figure S4). The results show that the $\mathbf{1 1 H}-\mathbf{1 5 H}$ intermediates are higher in energy than their anionic analogues (see Table S5), and that the overall activation barrier is slightly higher (see Table S4).

Another variant of pathway $\mathbf{C}$ has been investigated, where an axial $\mathrm{PPh}_{3}$ ligand is dissociated from 3, a feature which therefore leads to intermediates possessing two phosphine ligands in cis position (noted pathway $\mathbf{C}_{\mathbf{c i s}}$; see Figure S5). The full characterization of this pathway reveals that the later has very similar initiation and activation free energies (see Table S4). 
The neutral variant of this pathway has not been fully characterized (noted $\mathbf{C}_{\text {cisP/neut }}$ ), since the energy of the $\boldsymbol{c i s} \boldsymbol{P}-\mathbf{T S}_{\mathbf{1 3 H}-\mathbf{1 4 H}}$ transition state is found to be significantly higher (by 7.9 $\mathrm{kcal} / \mathrm{mol}$ ) than its trans- phosphine analogue (see the relative energies in Table S1 and compare $\mathbf{C}_{\text {cisP/neut }}$ and $\mathbf{C}_{\text {neutral }}$ pathways in Table S4).

\section{Pathway D: Phosphine dissociation as an initiation step.}

Description of reaction pathway $D$. Intermediate 15 possesses a vacant site and could alternatively react with a solvent molecule instead of undergoing a recoordination of a phosphine ligand as described in pathway $\mathbf{C}$. We explored this possibility and found that the coordination of one methanol molecule is easily achieved if $\mathbf{1 5}$ is protonated first (to afford 15H; $\Delta \mathrm{G}_{15 \rightarrow 15 \mathrm{H}}=-2.0 \mathrm{kcal} / \mathrm{mol}$ and $\left.\Delta \mathrm{G}_{15 \mathrm{H} \rightarrow 16 \mathrm{Hb}}=4.3 \mathrm{kcal} / \mathrm{mol}\right),{ }^{45}$ whereas the direct $\mathrm{MeOH}$ coordination to $\mathbf{1 5}$ (to afford $\mathbf{1 6})$ is more demanding thermodynamically $\left(\Delta \mathrm{G}_{15 \rightarrow 16}=+11.3\right.$ kcal/mol; see Figure S6 and Table S6). The resulting complex 16Hb therefore possesses both $\mathrm{H}_{2}$ and $\mathrm{MeOH}$ ligands. The next steps consist of the decoordination of $\mathrm{H}_{2}$ to afford $\mathbf{1 7}(+7.3$ $\mathrm{kcal} / \mathrm{mol})$, followed by a deprotonation of the methanol ligand $(-5.6 \mathrm{kcal} / \mathrm{mol})$, therefore generating the previously considered intermediate 11 (Figure 8). The following steps are identical to those described for Pathway $\mathbf{C}$, i.e. the $\beta$-hydride transfer from $\mathbf{1 1}$ and the decoordination of the $\mathrm{HCHO}$ product lead to $\mathbf{1 5}$ and close the catalytic cycle.

The reaction profile indicates that intermediate $\mathbf{1 3}$ is the resting state of this pathway and that the rate-limiting steps are the aldehyde decoordination (occurring via $\mathbf{T S}_{\mathbf{1 3 - 1 4}}$ ) and the $\mathrm{H}_{2}$ elimination $\left(\mathbf{T S}_{\mathbf{1 6 H b}-17}\right)$. Computations at the ECP3 level show, however, that the latter is slightly higher in energy than the former, resulting to an overall activation free energy of 27.0 $\mathrm{kcal} / \mathrm{mol}$ for this pathway (see Table 2). We also note that this mechanism also requires an initiation step, consisting of the decoordination of the equatorial $\mathrm{PPh}_{3}$ ligand from $\mathbf{1 5 H}$. The latter is found to be reasonably demanding thermodynamically $(10.9 \mathrm{kcal} / \mathrm{mol}$ at the ECP3 level, see Table 2). 


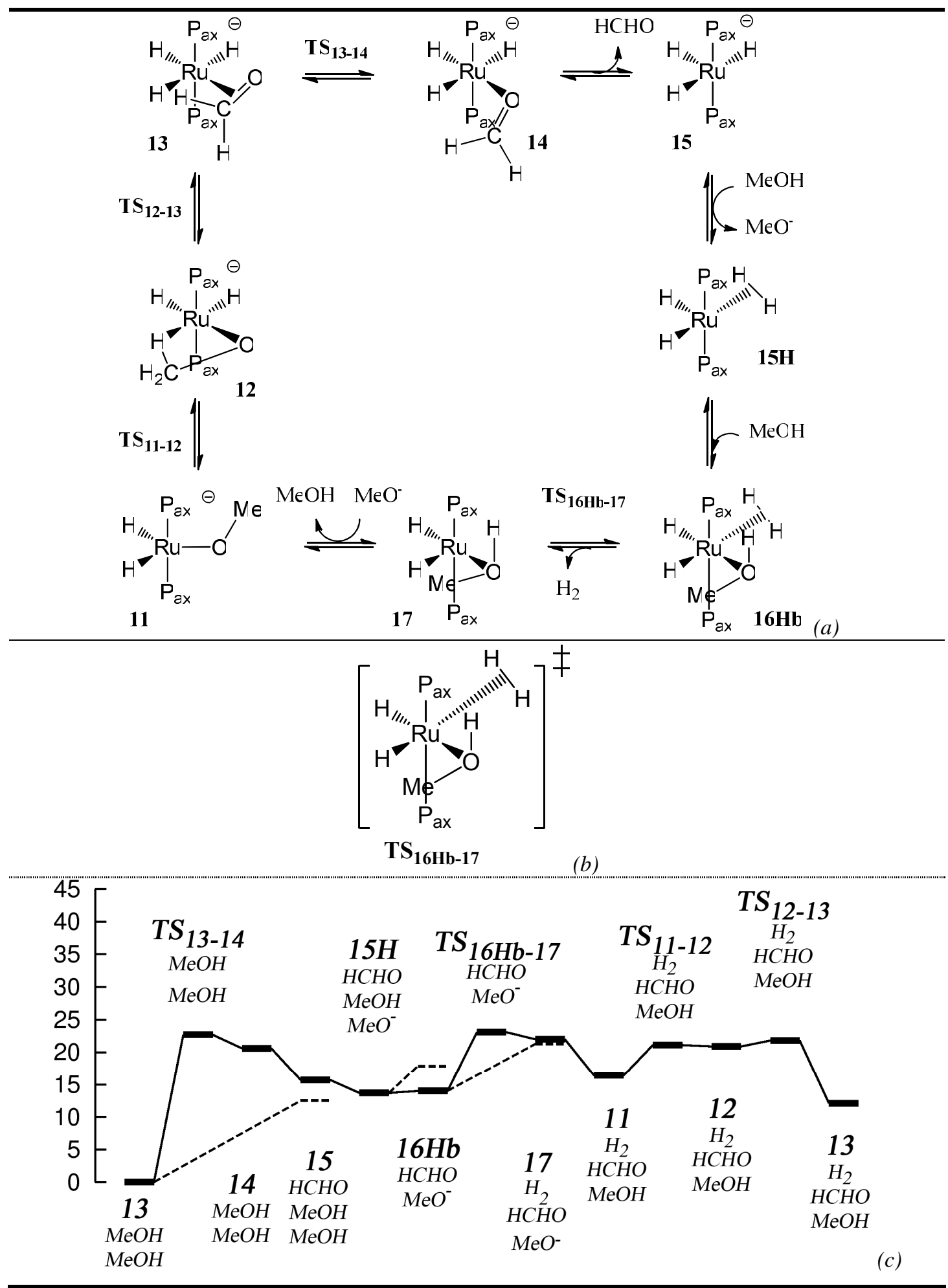

Figure 8: Reaction pathway D. See Figure 2 for a definition of labels $(a),(b),(c)$. 


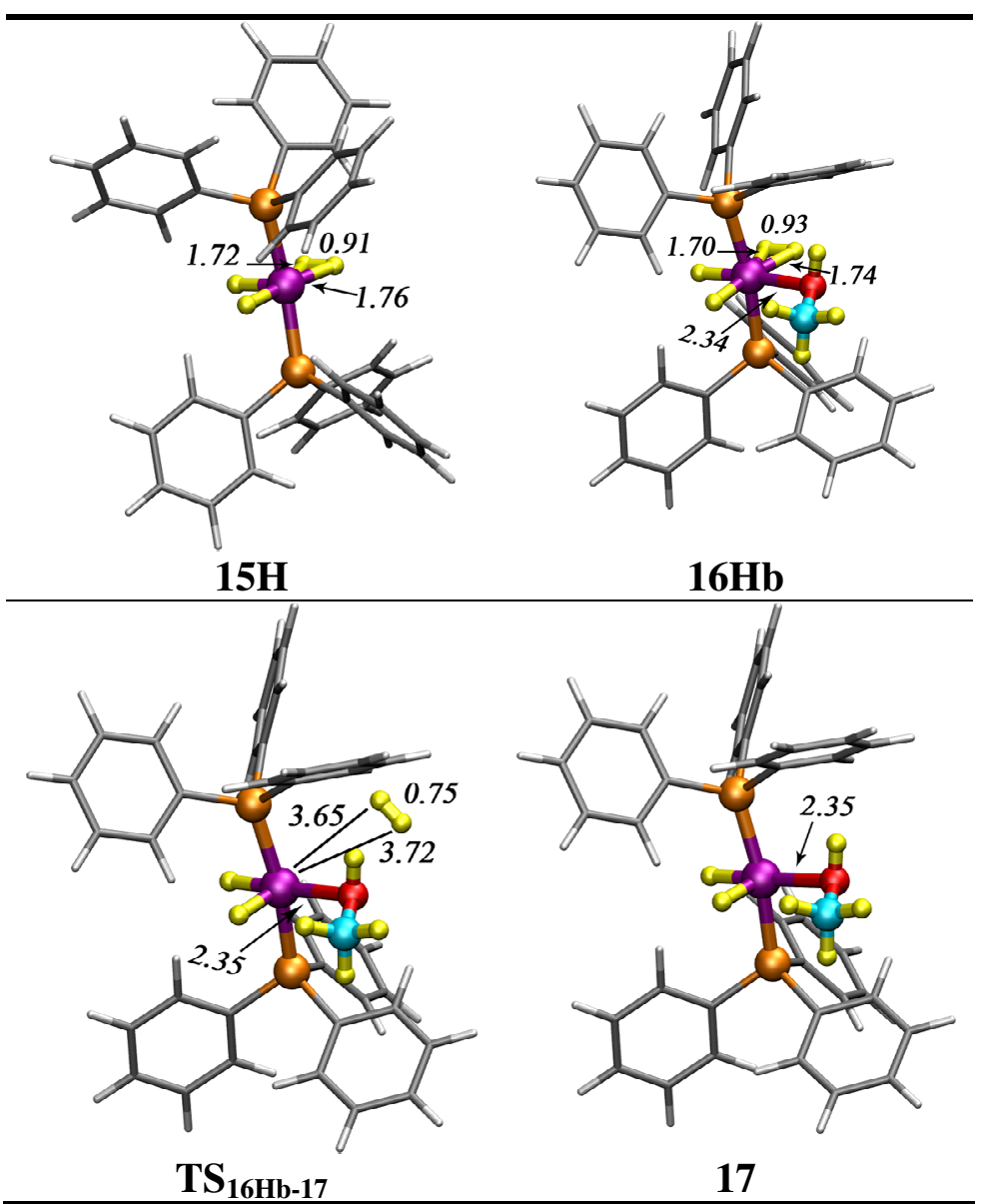

Figure 9: Structures of intermediates and transitions states involved in pathway $\mathbf{D}$, including selected inter-atomic distances (in $\AA$ ).

Structural features. The tetra-hydride complex $\mathbf{1 5 H}$ possesses two hydride ligands, one $\mathrm{H}_{2}$ ligand $\left(\mathrm{d}_{\mathrm{H}-\mathrm{H}}=0.91 \AA\right)$ and a vacant site in the equatorial plane (see Figure 9). No stationary point could be found for a " $\mathrm{D}_{4 \mathrm{~h}}$-like" classical hydride analogue. We note that the structure of the $\left[\mathrm{RuH}_{2}\left(\mathrm{H}_{2}\right)\left(\mathrm{PPh}_{3}\right)_{2}\right]$ moiety remains almost unaltered after coordination of one $\mathrm{MeOH}$ molecule (compare $\mathbf{1 5 H}$ and $\mathbf{1 6 H b}$ in Figure 9), the latter being oriented in the equatorial plane pointing its alcohol hydrogen towards one $\mathrm{PPh}_{3}$ ligand. As observed above, the transition state corresponding to the $\mathrm{H}_{2}$ elimination ( $\mathbf{T S}_{\mathbf{1 6 H b}-17}$ ) involves quite long $\mathrm{Ru}-\mathrm{H}$ distances (ca. $3.7 \AA$ ), whereas the orientation and the Ru-O distances of the MeOH ligands remain unchanged (ca. $2.35 \AA$ ) even after full dissociation of the $\mathrm{H}_{2}$ moeity. As observed above, the decoordination of $\mathrm{H}_{2}$ occurs along with a relaxation of the $\left[\mathrm{RuH}_{2}\left(\mathrm{PPh}_{3}\right)_{3}\right]$ moiety (Figure S2), and the deformation energy is estimated to be $3.6 \mathrm{kcal} / \mathrm{mol}$ in $\mathbf{1 6} \mathbf{H b}$ and is almost zero in $\mathbf{T S}_{\mathbf{1 6 H b - 1 7}}{ }^{44}$ 


\section{Discussion}

Substrate coordination and role of the base. Two possibilities have been investigated for the insertion of the substrate in the catalytic cycle by considering the coordination of either the $\mathrm{MeOH}$ or the $\mathrm{MeO}^{-}$moieties. In pathways $\mathbf{A - C}$, the direct coordination of $\mathrm{MeOH}$ is shown to be more thermodynamically demanding than the coordination of $\mathrm{MeO}^{-}$(see Table 1). This step therefore involves a preliminary deprotonation of the substrate by the base, as suggested by Cole-Hamilton et al. $^{7}$ However, this feature is not a general rule, since we found an opposite behavior in the case of pathway $\mathbf{D}$, where the direct coordination of $\mathrm{MeOH}$ to $\mathbf{1 5 H}$, followed by the deprotonation of the coordinated alcohol, is found to be the easiest route (see Figure S6). The presence of a base is also beneficial for the formation of intermediate $\mathbf{3 H}$ involved in pathways $\mathbf{B}$ (Figure 4) and $\mathbf{C}_{\text {neutral }}$ (Figure S4). In absence of base, this intermediate would be afforded by addition of $\mathrm{MeOH}$ to 2 , followed by the intramolecular transfer of the alcohol hydrogen via $\mathbf{T S}_{\mathbf{2} \rightarrow \mathbf{6}}$. However, this step involves a high kinetic barrier $(14.3 \mathrm{kcal} / \mathrm{mol})$, whereas it is not activated when performed via 3 , i.e. by a sequence of proton exchanges with the base. ${ }^{46}$ We note that such a high barrier is consistent with the studies of Delbecq et al. ${ }^{13 b}$ and Joo et al. ${ }^{13 c}$ where this process has been described in the context of the hydrogenation of $\alpha, \beta$-unsaturated aldehydes. ${ }^{47}$ We note that the base can also react with the $\mathrm{Ru}$ center of catalyst complexes and therefore allows to modulate the number of hydride and/or $\mathrm{H}_{2}$ ligands at the metal. As a result, we found that anionic intermediates and transition states are generally lower in energy than their neutral conjugated acids (see Table S5), the former naturally leading to more kinetically favorable pathways. We note that the positive effect of the base is consistent with the early studies of Cole-Hamilton et al. ${ }^{7}$ who demonstrated an enhancement of the reaction rate upon an addition of small amounts of $\mathrm{NaOH} .{ }^{7 \mathrm{~b}}$ However, a full understanding of its role would require the consideration of the full catalytic system and, in particular, to take into account the decarbonylation and aldol condensation side-reactions. However, our results points to the effect of the base on the dehydrogenation reaction itself, a feature which has not been reported in such details so far.

$\boldsymbol{\beta}$-hydride transfer. In the four investigated pathways, the $\beta$-hydride transfer is found to occur via the formation of a 4-membered ring (Ru-O-C-H). In pathway $\mathbf{A}$, the latter is observed within a 7-coordinated complex and the resulting $\mathrm{HCHO}$ product is not coordinated to the metal at the end of the transfer step. This feature contrasts with other pathways, where prior 
dissociation of $\mathrm{H}_{2}$ or $\mathrm{PPh}_{3}$ facilitates the process due to the formation of a vacant site at the $\mathrm{Ru}$ center. This vacant site first allows the formation of an agostic interaction which initiates the transfer, and next allows the coordination of the $\mathrm{HCHO}$ product to the metal. We note that the intermediacy of a such four-membered ring is consistent with the early findings of Itagaki et al. who studied dehydrogenation at a Ru center in presence of acetate ligands, ${ }^{12}$ and is also found in numerous studies of the reverse aldehyde hydrogenation reactions ${ }^{13 b, 13 c}$ and hydrogen-transfer ${ }^{14 \mathrm{a}, 14 \mathrm{~b}}$ reactions. $^{48}$

Phosphine dissociation. Pathways $\mathbf{C}$ and $\mathbf{D}$ involve the decoordination of one phosphine ligands occurring either from $\mathbf{3}$ (in $\mathbf{C}$ ) or from $\mathbf{1 b}$ (in $\mathbf{D}$ ). We found that this process is thermodynamically facile (from ca. $3 \mathrm{kcal} / \mathrm{mol}$ in $\mathbf{3}$ to $c a .11 \mathrm{kcal} / \mathrm{mol}$ in $\mathbf{1 b}$ ) and this result is therefore consistent with the presence of a phosphine dissociation pre-equilibrium, as suggested by Shinoda et al. ${ }^{10}$ We both considered the possibility that the dissociated ligand recoordinates in each catalytic cycle (in $\mathbf{C}$ ) or remains uncoordinated (in D), and these two paths are found to be feasible kinetically. The dissociation of a phosphine ligand is also consistent with the ${ }^{1} \mathrm{H}$ NMR characterization, under non-catalytic conditions, of the $\left[\mathrm{RuH}_{3}\left(\mathrm{PPh}_{3}\right)_{2}\right]^{-}$trihydride complex ${ }^{11 \mathrm{a}}$ which is involved in pathways $\mathbf{C}$ and $\mathbf{D}$ (intermediate 15). This complex is obtained from its pentahydride $\left[\mathrm{RuH}_{5}\left(\mathrm{PPh}_{3}\right)_{2}\right]^{-}$analogue, which has also been characterized by ${ }^{1} \mathrm{H}$ and ${ }^{31} \mathrm{P} \mathrm{NMR} .{ }^{49}$ According to NMR, $\left[\mathrm{RuH}_{3}\left(\mathrm{PPh}_{3}\right)_{2}\right]^{-}$possesses its two phosphine ligands in a cis- position, whereas the NMR spectrum of $\left[\mathrm{RuH}_{5}\left(\mathrm{PPh}_{3}\right)_{2}\right]^{-}$is found to be "consistent with a pentagonal bipyramidal structure or with a fluxional structure having a low activation barrier for interconversion". ${ }^{11 a}$ These observations are in accord with our calculations since we found that, in the case of $\left[\mathrm{RuH}_{3}\left(\mathrm{PPh}_{3}\right)_{2}\right]^{-}$, the cis- isomer is ca. 8 $\mathrm{kcal} / \mathrm{mol}$ more stable than its trans- analogue 15 (see Table S1). We also investigated cisforms of other intermediates and transition states involved in pathway $\mathbf{C}$ and found that the pairs of isomers are generally close in energy (within a range of $+/-5 \mathrm{kcal} / \mathrm{mol}$ ). Moreover, the full characterization of a variant of $\mathbf{C}$ involving cis- complexes only (pathway cisP; see Figure S5) revealed that they possess similar reaction profiles and almost identical activation energies (see Table S4). Our results therefore suggest that both forms are reactive and that they could be involved in competitive pathways.

Aldehyde decoordination. In pathways B-D, the aldehyde decoordination step is particularly demanding kinetically due to the presence of a high-energy transition state corresponding to a 
$\eta^{2}-\eta^{1}$ slippage of the coordinated product preceding its full decoordination. In all investigated pathways, the $\eta^{2}$ form is preferred and both the height of the barrier and the energy difference between the two coordination modes are found to depend on the number of phosphine ligands attached to the metal, the global charge of complexes and the cis-/transposition of $\mathrm{PPh}_{3}$ ligands. These results are in agreement with the study of Delbecq et al., ${ }^{50}$ who investigated the binding of formaldehyde to several types of organometallic fragments. They found that HCHO can exhibit a high back-bonding interaction and that the latter can be strongly affected by the nature of the ligands. Studies of model Ru complexes at the low RIBP86/ECP1 level (see Table S7) suggest that back-bonding is especially important within Ru hydride complexes, since we found that a $\eta^{1}$ coordination is slightly preferred for $\left[\mathrm{RuCl}_{2}\left(\mathrm{PH}_{3}\right)_{3}(\mathrm{HCHO})\right]$ (by $1.9 \mathrm{kcal} / \mathrm{mol}$, in accord with Delbecq et al. ${ }^{50}$ results) whereas a $\eta^{2}$ coordination mode is strongly favored in the case of its hydride analogue $\left[\mathrm{RuH}_{2}\left(\mathrm{PH}_{3}\right)_{3}(\mathrm{HCHO})\right]$ (by $\left.15.7 \mathrm{kcal} / \mathrm{mol}\right)$. The cis-/trans- position of the hydride ligands is found to have a small influence on the relative energies $(3.0 \mathrm{kcal} / \mathrm{mol})$, as has the replacement of $\mathrm{PH}_{3}$ by $\mathrm{PPh}_{3}$ ligands $(2.6 \mathrm{kcal} / \mathrm{mol})$. The high energy barrier is therefore expected to stem from the breaking of such back-bonding interaction and the further stabilization of the $\eta^{1}$ form would correspond to an optimal dative bond between $\mathrm{HCHO}$ and the Ru complexes. We note that the $\eta^{2} / \eta^{1}$ relative energies can be significantly affected by the nature of the carbonylated ligand (see below), since a preference for a $\eta^{1}$ coordination mode has been found for a serie of $\alpha, \beta$-unsaturated aldehydes. ${ }^{13 a}$ For these substrates, transition states between the $\eta^{1}$ and $\eta^{2}$ forms have be characterized elsewhere ${ }^{13 b} 13 \mathrm{c}$ and their structures are reminiscent to those described herein (namely $\mathbf{T} \mathbf{S}_{\mathbf{9 - 1 0}}, \mathbf{T S}_{\mathbf{1 3 - 1 4}}$, and $\mathbf{T S}_{\mathbf{1 3 H - 1 4 H}}$ ). 


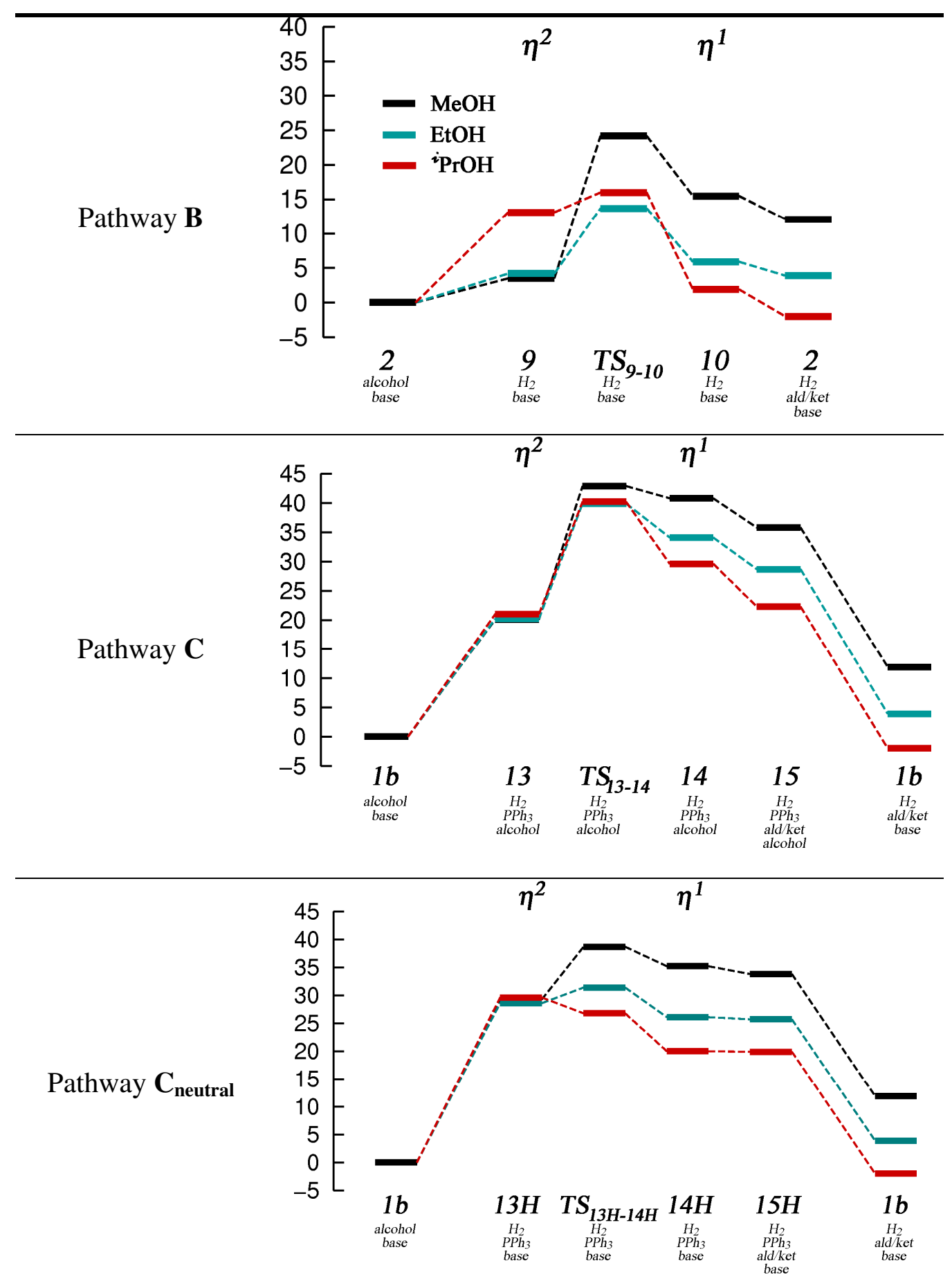

Figure 10: Free energy profiles (kcal/mol) for pathways $\mathbf{B}, \mathbf{C}$ and $\mathbf{C}_{\text {neutral }}$, comparing $\mathrm{MeOH}$ (black), EtOH (blue) and ${ }^{i} \mathrm{PrOH}($ red) as starting substrates. Only steps corresponding to the $\eta^{2} / \eta^{1}$ slippage and the subsequent aldehyde (or ketone) decoorination are represented. Free energies are computed in solution at the B97-D/ECP2 level and without BSSE correction (refined values for the rate-limiting barriers are given in Table 2). 
Other alcohol substrates and consequences on the reaction efficiency. The interesting bonding behavior of substituted aldehydes to $\mathrm{Ru}$ complexes led us to investigate the coordination properties of ethanal and acetone which would result from the dehydrogenation of EtOH and ${ }^{i} \mathrm{PrOH}$, respectively. These substrates have also been investigated in the original study of Morton and Cole-Hamilton, and they found that significantly higher turnover frequencies are obtained compared to $\mathrm{MeOH} .{ }^{7 \mathrm{a}} \mathrm{We}$ first focused on the decoordination process of the products in Pathways $\mathbf{B}, \mathbf{C}$ and $\mathbf{C}_{\text {neutral }}$ (i.e. an analogous pathway to $\mathbf{C}$ involving protonated intermediates), which all involve a $\eta^{2}-\eta^{1}$ slippage of the coordinated aldehyde (or ketone). Figure 10 gathers the results of these calculations and clearly shows that the nature of the product has a strong influence on the $\eta^{2} / \eta^{1}$ relative energies. The nature of the catalyst complex itself is also important, since a very different behavior is observed for each pathway. In Pathway $\mathbf{B}$, the preference for a $\eta^{2}$ coordination observed in the case of HCHO moves toward quasi isoenergetic $\eta^{2} / \eta^{1}$ forms with $\mathrm{MeCHO}$, whereas a $\eta^{1}$ coordination mode is clearly preferred for $\mathrm{Me}_{2} \mathrm{CO}$. This finding is consistent with observations in the solid state, where a $\eta^{2}$ coordination mode is observed in the related $\left[\mathrm{Os}\left(\mathrm{PPh}_{3}\right)_{2}(\mathrm{CO})_{2}(\mathrm{HCHO})\right]$ complex, ${ }^{51}$ and where acetone is mainly $\eta^{1}$-coordinated to transition metals. ${ }^{52}$

The height of the barrier corresponding to the slippage decreases with increasing driving force, i.e. from $\mathrm{HCHO}$ to $\mathrm{Me}_{2} \mathrm{CO}$. In pathway $\mathbf{C}$, involving anionic bis-phosphine complexes, the three substrates are equally well bonded to the metal when $\eta^{2}$-coordinated (in 13), whereas the $\eta^{1}$ form is gradually stabilized when going from $\mathrm{HCHO}$ to $\mathrm{Me}_{2} \mathrm{CO}$. Interestingly, the corresponding activation energies are found to be very similar in this case. This behavior contrasts with the one obtained for pathway $\mathbf{C}_{\text {neutral }}$ in which both transition state and $\eta^{1}$ forms are stabilized with higher substrates. A common feature of the three studied pathways is that the nature of the substrate has little influence on the full decoordination energies.

Following this analysis of the bonding properties of the carbonylated products, we investigated the influence of the substrate on the kinetic of the reaction by re-computing the highest energies barriers for A-D with EtOH and ${ }^{i} \mathrm{PrOH}$ as starting substrates (see Table 2). In most cases, the nature of the alcohol does not influence the nature of the rate-limiting steps, and the only exception is found for pathway $\mathbf{D}$ where the highest barrier is found between 
15H and $\mathbf{T S}_{\mathbf{1 3 - 1 4}}$ with ${ }^{i} \mathrm{PrOH}$ (instead of $\mathbf{1 3}$ and $\mathbf{T S} \mathbf{S}_{\mathbf{1 6 H b}-\mathbf{1 7}}$ with other alcohols). This is clearly shown in Figure S8, where we report the full corresponding reaction profile: with isopropanol, the energy level of $\mathbf{1 6 H b}$ is shifted down due to a more stable $\eta^{1}-\mathrm{Me}_{2} \mathrm{CO}$ complex (intermediate 15), and the highest energy level therefore corresponds to $\mathbf{T S}_{\mathbf{1 3 - 1 4}}$ which is little affected by the nature of the substrate (vide supra). The overall activation barriers systematically decreases when going from $\mathrm{MeOH}$ to ${ }^{i} \mathrm{PrOH}$ (Table 2), which is consistent with the trend of experimental reaction turnover frequencies reported by Morton and ColeHamilton. ${ }^{7 a}$ Understanding this behavior is not straightforward since it does not only stem from the intrinsic (gas-phase) reaction energies, but also from the contributions of solvation and thermochemical corrections. The reaction is also favored thermodynamically with higher alcohols since the global reaction free energy gradually decreases from $\mathrm{MeOH}$ to ${ }^{i} \mathrm{PrOH}$ (compare final $v s$ initial energy levels in Figure 10). ${ }^{53}$

Reaction kinetics and multiple reaction pathways. Pathways A-D involve rate-limiting steps of different nature: $\boldsymbol{i}$. in pathway $\mathbf{A}$, the latter correspond to the $\beta$-hydride transfer (occurring in $\mathbf{T S}_{3-4}$ ), ii. in pathways $\mathbf{B}$ and $\mathbf{D}$, the reaction is rate-limited by the decoordination of the $\mathrm{H}_{2}$ product (in $\mathbf{T} \mathbf{S}_{\mathbf{3 H b}-\mathbf{7}}$ and $\mathbf{T} \mathbf{S}_{\mathbf{1 6 H b - 1 7}}$, respectively), and $\mathbf{i i i}$. in pathway $\mathbf{C}$, the rate-limiting step is the partial decoordination of HCHO ( $\left.\mathbf{T S}_{\mathbf{1 3 - 1 4}}\right)$. We also note that pathways $\mathbf{B}$ and $\mathbf{D}$ require an activation step, namely the decoordination from $\mathbf{1 b}$ of $\mathrm{H}_{2}$ (in $\mathbf{B}$ ) and $\mathrm{PPh}_{3}$ (in $\mathbf{D}$ ). As shown in Table 2, we found that all theses pathways possess very close activation energies, ranging from $27.0 \mathrm{kcal} / \mathrm{mol}$ for pathway $\mathbf{D}$ to $32.1 \mathrm{kcal} / \mathrm{mol}$ for pathway $\mathbf{B}$. On the other hand, initiation free energies are found to be rather small $(4.3 \mathrm{kcal} / \mathrm{mol}$ in $\mathbf{B}$ and $10.9 \mathrm{kcal} / \mathrm{mol}$ in D). These features therefore suggest that the four investigated pathways are competitive since they are all accessible kinetically. Moreover, we note that A-D are strongly interlocked (see Figure 1), since intermediates $\mathbf{3}, \mathbf{5}, \mathbf{1 5}$ and their protonated analogues (i.e. $\mathbf{3 H}, \mathbf{1 b}$ and $\mathbf{1 5 H}$ respectively) are "at the crossing" of the different pathways, therefore providing links from one route to another, a feature which is expected to be beneficial to the overall kinetic of the system. As a matter of comparison, we found interesting to estimate how this behavior depends on thermodynamic conditions and we recomputed the overall activation energies at the lower temperature of $64{ }^{\circ} \mathrm{C}$ (i.e. at the boiling point of methanol) and we found that, in this case, pathways $\mathbf{A}, \mathbf{B}$ and $\mathbf{D}$ still remain competitive and that pathway $\mathbf{C}$ (as well as its neutral and cis-phosphine analogues) is slightly penalized kinetically (see Table S4). Similarly, when varying the nature of the substrate, we found that $\mathbf{A}, \mathbf{B}$ and $\mathbf{C}$ remain 
competitive, whereas pathway $\mathbf{D}$ is favored with ethanol and isopropanol (see Table 2).

\section{Conclusion}

To summarize, we applied modern DFT techniques to elucidate the mechanism of alcohol dehydrogenation of alcohols catalyzed by a Ruthenium / triphenylphosphine catalyst. The modeling of "real" bulky $\mathrm{PPh}_{3}$ ligands revealed the importance of steric effects and allowed us to model the key ligand dissociation steps. Comparison between model and real phosphines, i,e. $\mathrm{PH}_{3}$ vs $\mathrm{PPh}_{3}$, showed that the latter induces higher kinetic barriers. The initially proposed mechanism of Morton and Cole-Hamilton ${ }^{7 \mathrm{a}}$ is found to be kinetically accessible, as are three other mechanisms proposed in this study. The computations also furnish insights into the role of the base, which is threefold: $i$. it facilitates the coordination of the substrate (pathways A-C), ii. it catalyzes intramolecular proton transfers, and iii. it allows to regulate the number of hydrogen atoms coordinated to the metal, a feature which can lead the system to more favorable pathways. The investigation of other alcohols substrates revealed that the reaction is kinetically favored with higher alcohols, a feature generally due to an easier aldehyde/ketone decoordination step. The main result of our study is that the four investigated pathways are found to possess close overall activation free energies, and should therefore be competitive. This feature may well be at the origin of the good efficiency of this reaction, in line with the emerging view ${ }^{54}$ that providing several reaction channels is kinetically beneficial for catalytic reactions.

Acknowledgment: We wish to thank EaStCHEM for support and access to the EaStCHEM Research Computing Facility. We also thank Dr. H. Früchtl for technical support and Prof. D. J. Cole-Hamilton for fruitful discussions.

Supporting Information Available: Relative energies of selected isomers, intramolecular BSSE correction terms, description of other investigated pathways mentioned in the text, and Cartesian coordinates of selected complexes. This material is available free of charge via the Internet at http://pubs.acs.org. 


\section{References}

(1) Navarro, R. M.; Pena, M. A.; Fierro, J. L. G. Chem. Rev. 2007, 107, 3952.

(2) see e.g.: Cortright, R. D.; Davda, R. R.; Dumesic, J. A. Nature 2002, 418, 964.

(3) Johnson, T. C.; Morris, D. J.; Wills, M. Chem. Soc. Rev. 2010, 39, 81.

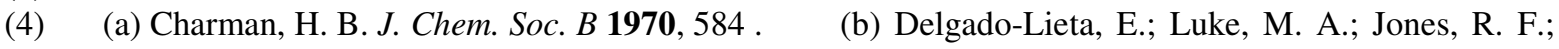
Cole-Hamilton, D. J. Polyhedron 1982, 1, 839.

(5) Dobson, A.; Robinson, S. D. Inorg. Chem. 1977, 16, 137.

(6) (a) Morton, D.; Cole-Hamilton, D. J. J. Chem. Soc., Chem. Commun. 1987, $248 . \quad$ (b) Morton, D.; Cole-Hamilton, D. J.; Schofield, J. A.; Pryce, R. J. Polyhedron 1987, 6, 2187. (c) Rybak, W. K.; Ziólkowski, J. J. J. Mol. Catal. 1981, 11, $365 . \quad$ (d) Jung, C. W.; Garrou, P. E. Organometallics 2002, 1, 658. (e) Ligthart, G. B. W. L.; Meijer, R. H.; Donners, M. P. J.; Meuldijk, J.; Vekemans, J. A. J. M.; Hulshof, L. A. Tetrahedron Lett. 2003, 44, 1507. (f) Shinoda, S.; Itagaki, H.; Saito, Y. J. Chem. Soc., Chem. Commun. 1985, 860. Catal. 1991, 67, 185.

(7) (a) Morton, D.; Cole-Hamilton, D. J. J. Chem. Soc., Chem. Commun. 1988, $1154 . \quad$ (b) Morton, D.; Cole-Hamilton, D. J.; Utuk, I. D.; Paneque-Sosa, M.; Lopez-Poveda, M. J. Chem. Soc. Dalton Trans. 1989, 489.

(8) (a) Adair, G. R. A.; Williams, J. M. J. Tetrahedron Lett. 2005, 46, $8233 . \quad$ (b) Zhanga, J.; Gandelmana, M.; Shimonb, L. J. W.; Milstein, D. Dalton Trans. 2007, 107.

(9) (a) Junge, H.; Beller, M. Tetrahedron Lett. 2005, 46, 1031. (b) Junge, H.; Loges, B.; Beller, M. Chem. Commun. 2007, 522.

(10) Yang, L.-C.; Ishida, T.; Yamakawa, T.; Shinoda, S. J. Mol. Catal. A 1996, 108, 87.

(11) (a) Fordyce, W. A.; Wilczynski, R.; Halpern, J. J. Organomet. Chem. 1985, 296, 115. (b) Gusev, D. G.; Vymenits, A. B.; Bakhmutov, V. I. Inorg. Chimica. Acta 1991, 179, 195. (c) Halpern, J. Pure \& Appl. Chem. 1987, 59, 173. (d) Linn, D. E.; Halpern, J. J. Am. Chem. Soc. 1987, 109, 2969.

(12) Itagaki, H.; Koga, N.; Morokuma, K.; Saito, Y. Organometallics 1993, 12, 1648.

(13) (a) Joubert, J.; Delbecq, F. J. Organomet. Chem. 2006, 691, 1030. (b) Joubert, J.; Delbecq, F. Organometallics 2006, 25, 854. (c) Rossin, A.; Kovacs, G.; Ujaque, G.; Lledos, A.; Joo, F. Organometallics 2006, 25, 5010 .

(14) (a) Alonso, D. A.; Brandt, P.; Nordin, S. J. M.; Andersson, P. G. J. Am. Chem. Soc. 1999, $121,9580$. (b) Yamakawa, M.; Ito, H.; Noyori, R. J. Am. Chem. Soc. 2000, 122, $1466 . \quad$ (c) Handgraaf, J.-W.; Meijer, E. J. J. Am. Chem. Soc. 2007, 129, $3099 . \quad$ (d) Bacchi, A.; Balordi, M.; Cammi, R.; Elviri, L.; Pelizzi, C.; Picchioni, F.; Verdolino, V.; Goubitz, K.; Peschar, R.; Pelagatti, P. Eur. J. Inorg. Chem. 2008, $2008,4462$.

(15) Crabtree, R. H.; Hamilton, D. G. J. Am. Chem. Soc. 1986, 108, 3124.

(16) We note that this study has been performed under different experimental conditions since it involves the $\left[\mathrm{RuCl}_{2}\left(\mathrm{PPh}_{3}\right)_{3}\right]$ precursor and has been performed in absence of base at a temperature of $64{ }^{\circ} \mathrm{C}$, whereas the Cole-Hamilton system is based on $\left[\mathrm{RuH}_{2}\left(\mathrm{X}_{2}\right)\left(\mathrm{PPh}_{3}\right)_{3}\right]\left(\mathrm{X}_{2}=\mathrm{N}_{2}\right.$ or $\left.\mathrm{PPh}_{3}\right)$ and involves a small concentration of $\mathrm{NaOH}$ at $150{ }^{\circ} \mathrm{C}$.

(17) (a) Chaudret, B. N.; Cole-Hamilton, D. J.; Nohr, R. S.; Wilkinson, G. J. C. S. Dalton 1977, 1546.(b)

Van der Sluys, L. S.; Kubas, G. J.; Caulton, K. G. Organometallics 1991, 10, 1033.

(18) Sieffert, N.; Bühl, M. Inorg. Chem. 2009, 48, 4622.

(19) For a review see e.g.: Clapham, S. E.; Hadzovic, A.; Morris, R. H. Coord. Chem. Rev. 2004, $248,2201$.

(20) Grimme, S. J. Comput. Chem. 2006, 27, 1787.

(21) Recent research in quantum chemistry revealed that non-covalent interactions are indeed critically important when bulky phosphine ligands are considered and that the latter are poorly described by « traditional » functionals (e.g. B3LYP). See: (a) Zhao, Y.; Truhlar, D. G. Org. Lett. 2007, 9, $1967 . \quad$ (b) Zhao, Y.; Truhlar, D. G. J. Chem. Theory Comput. 2009, 5, 324. (c) Minenkov, Y.; Occhipinti, G.; Jensen, V. R. J. Phys. Chem. A 2009, 113, 11833. (d) see also our previous study in ref. 18

(22) Becke, A. D. Phys. Rev. A 1988, 38, 3098.

(23) (a) Perdew, J. P. Phys. Rev. B 1986, 33, 8822. $\quad$ (b) Perdew, J. P. Phys. Rev. B 1986, 34, 7406.

(24) Andrae, D.; Häußermann, U.; Dolg, M.; Stoll, H.; Preuß, H. Theor. Chim. Acta 1990, 77, 123.

(25) Structures have been determined without corrections for the basis set superposition error (BSSE), since the latter is found to have only a little influence on geometries. This feature has been investigated in our previous study on a similar tris-triphenylphosphine complex and only small structural differences have been obtained when going from ECP1 to the larger ECP2 basis set, where BSSE is expected to be smaller (see ref. 18). On the other hand, we note that the influence of BSSE on reaction energies has been carefully considered herein, and counterpoise energy corrections have been made for each investigated step.

(26) Generated automatically according to the procedure implemented in Gaussian 03. 
(27) Following the argument in Martin, R. L.; Hay, P. J.; Pratt, L. R. J. Phys. Chem. A 1998, 102, 35653573, where this simple procedure has been proposed as adjustment for the concentration of water molecules in the liquid, and where the necessary value for the pressure has been derived from the experimental density of liquid water. Such an elevated pressure is designed to model the change in entropy existing in condesned phase when the number of particle vary during a given reaction. For instance, in the case of the dissociation of $\mathrm{PPh}_{3}$ from $\mathbf{1 b}$ to afford $\mathbf{1 5 H}, \delta \mathrm{E}_{\mathrm{G}}=-22.9 \mathrm{kcal} / \mathrm{mol}$ at $\mathrm{P}=1354 \mathrm{~atm}$, whereas it is $-28.9 \mathrm{kcal} / \mathrm{mol}$ at $\mathrm{P}=1 \mathrm{~atm}$ (both at $\mathrm{T}=423 \mathrm{~K})$.

(28) (a) Gonzalez, C.; Schlegel, H. B. J. Chem. Phys. 1989, 90, 2154.

J. Phys. Chem. 1990, 94, 5523.

(29) Cowley, R. A.; Dilworth, J. R.; Maresca, C. A.; von Beckh W. Acta Cryst. E 2005, 61, m1237

(30) The propeller conformation is known to be the most stable one for the free $\mathrm{PPh}_{3}$ ligand. See $e . g$. Costello, J. F., Davies, S. G. J. Chem. Soc., Perkin. Trans. 2 1998, 1683.

(31) Ayscough, A. P.; Costello, J. F.; Davies, S. G. Tetrahedron: Asymmetry 2001, 12, 1621.

(32) Following the comment of a referee, we tested the influence of the density functional on the initiation and activation energies of Pathways A-D with the BP86, B3LYP, BP86-D, B3LYP-D and M06-L functionals (see Table S2). We found that B97-D and M06-L give similar activation barriers (within $\pm 2.6 \mathrm{kcal} / \mathrm{mol}$ on the average), whereas the traditional BP86 and B3LYP functionals lead to inconsistent results due to a lack of description of non-covalent interactions. BP86-D and B3LYP-D indeed give more consistent results, however, our previous study (ref. 18) revealed that B97-D is the best suited functional to model the key $\mathrm{PPh}_{3}$ dissociation step. More problematic is the case of $\mathrm{H}_{2}$ dissociation, where B97-D leads to a lower dissociation energy compared to M06-L. Comparison with the experimental enthalpy of activation for this process reported by Halpern et al (see ref. 32b) shows that, for this particular step, M06-L would be more suited since the B97-D value is underestimated by $c a .5 .2 \mathrm{kcal} / \mathrm{mol}\left(\Delta \mathrm{H}^{\neq \exp } \approx 17.9 \mathrm{kcal} / \mathrm{mol} ; \Delta \mathrm{H}^{\neq c a l c}=12.7 \mathrm{kcal} / \mathrm{mol}\right.$; computed by applying an enthalpy correction term $\left.\delta \mathrm{E}_{\mathrm{H}}=-2.8 \mathrm{kcal} / \mathrm{mol}\right)$. The good agreement between B97-D and M06-L in overall rate-limiting steps shows that this discrepancy is not systematic to B97-D and therefore comfort us in the choice of this functional to model this system. (b) Halpern, J.; Cai, L.; Desrosiers, P. J.; Lin, Z. J. Chem. Soc., Dalton Trans. 1991, 717.

(33) Grimme, S. J. Comput. Chem. 2004, 25, 1463.

(34) Piacenza, M.; Hyla-Kryspin, I.; Grimme, S. J. Comput. Chem. 2007, 28, 2275.

(35) Boys, S. F.; Bernardi, F. Mol. Phys. 1970, 19, 553.

(36) (a) Klamt, A.; Schüürmann, G. J. Chem. Soc. Perkin Trans. 2 1993, 5, 799. $\quad$ (b) The choice of this solvent model has been motivated by a recent study (Takano, Y.; Houk, K. N. J. Chem. Theory Comput., 2005, 1, 70-77) which showed that COSMO-based models give satisfactory hydration free energies of small anions and neutral molecules. Following the comment of a referee, we validated our approach by the computation of the protonation reaction of $\mathbf{5}$ ' by cyclohexanol in THF (to afford 1b), for which an equilibrium constant has been measured (see ref. $11 \mathrm{~d}$ ). We found a $\Delta \mathrm{G}$ value of $4.7 \mathrm{kcal} / \mathrm{mol}\left(\Delta \mathrm{E}, \delta \mathrm{E}_{\mathrm{BSSE}}, \delta \mathrm{E}_{\mathrm{Solv}}\right.$ and $\delta \mathrm{E}_{\mathrm{G}}$, contributions are $30.1,0.0,-22.2$ and $-3.3 \mathrm{kcal} / \mathrm{mol}$, respectively, at $\mathrm{T}=298.15, \mathrm{P}=1354 \mathrm{~atm}$ and with $\varepsilon=7.4257)$. This result is therefore in accord with the experiment $\left(\mathrm{K}_{\mathrm{eq}}=0.13\right.$, which corresponds to $\left.\Delta \mathrm{G}_{\mathrm{exp}} \approx 1.7 \mathrm{kcal} / \mathrm{mol}\right)$.

(37) Gaussian 03, Revision E.01, Pople, J. A. et al. Gaussian 03,

Gaussian, Inc., Pittsburgh, PA, 2003 (the full reference is given in Supporting Information).

(38) (a) Ahlrichs, R.; Baer, M. Haeser, M.; Horn H.; Koelmel, C. Chem. Phys. Lett., 1989, 162, 165. (b) Treutler, O.; Ahlrichs, R. J. Chem. Phys. 1995, 102, 346. (c) Arnim, M. v.; Ahlrichs, R. J. Comp. Chem. 1998, $19,1746$.

(39) Humphrey, W.; Dalke, A.; Schulten, K. J. Molec. Graphics 1996, 14, 33.

(40) No transition states could be located for the dissociation of the $\mathrm{MeOH}, \mathrm{HCHO}, \mathrm{MeO}^{-}$and $\mathrm{PPh}_{3}$ ligands from tris-triphenylphosphine complexes, presumably due to the shallow form of the underlying energy surface. Based on the experimental measurements of Sponsler et al. (Seetharaman, S. K.; Chung, M.-C.; Englich, U.; Ruhlandt-Senge, K.; Sponsler, M. B. Inorg. Chem. 2007, 46, 561) and on our computated energy profiles of dissociation of the ligands (in which small maxima are found at long metal-ligand distances; see Figure S7), we assume that the dissociation processes involve only late transition states with small extra activation barriers. The latter would be easily overcome under the reaction conditions and, because these steps are found between lowlying intermediate in the reaction profile, would affect neither the nature of the rate-limiting steps nor the overall activation barriers.

(41) Note that $\mathbf{4}$ is found as a result of the IRC calculation from $\mathbf{T S}_{\mathbf{3 - 4}}$ and effectively corresponds to a stationary point on the potential energy surface. However, this complex is not found on the BSSE corrected free energy surface, and is therefore expected to be rather unstable.

(42) Chan, A. S. C.; Shieh, H.-S. J. Chem. Soc., Chem. Commun. 1985, 1379.

(43) Using the simple Eyring equation, at $423 \mathrm{~K}$ such a barrier would correspond to a unimolecular rate constant on the order of $10^{-2} \mathrm{~s}^{-1}$ and, thus, to a half-life of few minutes. 
(44) These values are obtained by performing single points on the structures of $\mathbf{1 b}$ and $\mathbf{T} \mathbf{S S}_{\mathbf{1 b - 2}}$ in which the $\mathrm{H}_{2}$ moieties have been removed by hand. The resulting energies are then compared to the optimized energy of $\mathbf{2}$. The same procedure has been applied to compute the deformation energies involved in the $\mathrm{H}_{2}$ decoordination in the others pathways, i.e. in $\mathbf{3 H b}$ and $\mathbf{T S}_{3 \mathbf{H b}-7}$, relatively to $\mathbf{7}$ for pathway $\mathbf{B}$, and in $\mathbf{1 6 H b}$ and $\mathbf{T S}_{16 \mathrm{Hb}-17}$ relatively to $\mathbf{1 7}$ for pathway $\mathbf{D}$. These values are computed in the gas phase at the B97-D/ECP2 level $(\Delta \mathrm{E})$.

(45) The $\mathrm{MeOH}$ coordination is thermodynamically unfavorable by $2.3 \mathrm{kcal} / \mathrm{mol}$, however, given the large excess of $\mathrm{MeOH}$ (solvent) compared to $\mathrm{PPh}_{3}, \mathbf{1 6 H b}$ is expected to be accessible under reaction conditions.

(46) The different proton transfer processes involved in pathways A-D are considered to be non-activated. This assumption is based on the results of numerous computational studies on smaller systems, in which the corresponding free energy is found to evolve monotonically as proton transfer occurs. See e.g. the cases of the water self-hydrolysis reaction (Sprik, M. Chem. Phys. 2000, 258, 139), the deprotonation of solvated formic acid (Lee, J.-G.; Asciutto, E.; Babin, V.; Sagui, C.; Darden, T.; Roland, C. J. Phys. Chem. B 2006, 110, 2325) or the deprotonation of an aqueous uranyl metal complex (Bühl, M.; Kabrede, H. ChemPhysChem 2006, 7, 2290). However, the presence of such transition states in the particular case of the Ruthenium hydride complexes can not be fully precluded but their characterization seems hardly feasible by a static/continuum approach. Ab initio molecular dynamics simulations invloving explicit solvent molecules would be required for a meaningful investigation of proton transfers occuring between the solvent and $\mathrm{Ru}$ intermediates. Unfortunately, this approach is presently precluded by the size of the considered systems and the related large computational cost.

(47) We note that Delbecq et al. ${ }^{13 b}$ and Joo et al. ${ }^{13 c}$ investigated a reverse analogue of pathway $\mathbf{B}$ in which $\mathrm{PH}_{3}$ are used as model ligands and in which the presence of the base is not considered. The reaction profiles found in these studies are in qualitative agreement with our results, however qualitative comparisons are hardly possible since they considered different phosphine ligands and different substrates.

(48) For the less crowded complex 11, we have also explored the possibility of a $\mathrm{H}$-transfer via a less strained 6-membered ring involving the $\mathrm{OH}$ group of a second $\mathrm{MeOH}$ molecule. However, we could not find a feasible path for such a concerted, "outer sphere" mechanism (as it had been suggested in the case of transfer hydrogenation; see ref. 19).

(49) We note that the carbonylated $\left[\mathrm{RuH}_{3}(\mathrm{CO})\left(\mathrm{PPh}_{3}\right)_{2}\right]^{-}$complex has also been characterized, which may be involved in the decarbonylation side-reaction occuring in the system under scrutiny.

(50) Delbecq, F.; Sautet, P. J. Am. Chem. Soc. 1992, 114, 2446.

(51) Brown, K. L.; Clark, G. R.; Headford, C. E. L.; Marsden, K.; Roper, W. R. J. Am. Chem. Soc. 1979, $101,503$.

(52) In a corresponding search in the Cambridge Structural Database considering the " $\mathrm{M}\left(\mathrm{PC}_{3}\right)_{2} \eta^{2}-(\mathrm{HCHO})$ " fragment ( $\mathrm{M}$ being a group 8 metal) only one structure has been found corresponding to $\left[\mathrm{Os}\left(\mathrm{PPh}_{3}\right)_{2}(\mathrm{CO})_{2}(\mathrm{HCHO})\right]$. Another search considering " $\mathrm{M}\left(\mathrm{PC}_{3}\right)_{2} \eta^{2}-\left(\mathrm{Me}_{2} \mathrm{CO}\right)$ " led to no hit, whereas searching the " $\mathrm{M}\left(\mathrm{PC}_{3}\right)_{2} \eta$ - $-\left(\mathrm{Me}_{2} \mathrm{CO}\right)$ " fragment led to 30 hits.

(53) Compared to high-level $\operatorname{CCSD}(\mathrm{T})$ or to experimental data, the absolute reaction enthalpies for dehydrogenation of the alcohols are notably underestimated at the B97-D level, but the relative sequence is very well captured at the DFT level (see Table S8).

(54) Schneider, N.; Finger, M.; Haferkemper, C.; Bellemin-Laponnaz, S.; Hofmann, P.; Gade, Lutz H. Chem. Eur. J. 2009, 15, 11515.

\section{Table of Content graphic:}

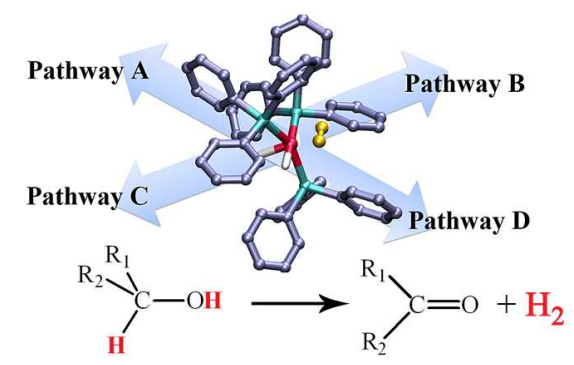

